\title{
Hard carbon key properties allow for the achievement of high Coulombic efficiency and high volumetric capacity in Na-ion batteries
}

Adrian Beda, ${ }^{a b}$ François Rabuel, ${ }^{c d}$ Mathieu Morcrette, ${ }^{c d}$ Stephan Knopf, ${ }^{a b}$ Pierre-Louis Taberna, $^{\text {de }}$ Patrice Simon ${ }^{d e}$ and Camelia Matei Ghimbeu $* a b d$

${ }^{a}$ Université de Haute-Alsace, Institut de Science des Matériaux de Mulhouse (IS2M), CNRS, UMR 7361, F-68100 Mulhouse, France

${ }^{\text {b }}$ Université de Strasbourg, F-67081 Strasbourg, France

${ }^{\mathrm{c}}$ Université de Picardie Jules Verne, Laboratoire de Réactivité et Chimie des Solides (LRCS), UMR 7314 CNRS, HUB de l'Energie, 80039 Amiens, France

${ }^{\mathrm{d}}$ Réseau sur le Stockage Electrochimique de l'Energie (RS2E), HUB de l'Energie, FR CNRS 3459, 80039 Amiens, France

e Université de Toulouse, CIRIMAT, UMR-CNRS 5085, F-31062 Toulouse, France

* Corresponding authors

E-mail: camelia.ghimbeu@uha.fr 


\begin{abstract}
The volumetric capacity and the initial Coulombic efficiency are features of major importance when it comes to the development of full-cell batteries, and are thus key characteristics to boost Na-ion batteries (NIBs) commercialization. To allow the improvement of these parameters, several hard carbon properties that are rarely addressed, such as tapped density and electrode porosity after calendaring, were investigated herein in relation with their physico-chemical characteristics and electrochemical performance. A series of sustainable and scalable synthesized hard carbon spheres with controlled properties were used in this purpose. It was found that the electrode porosity after calendaring decreases rather linearly with the graphite interlayer space $\left(d_{002}\right)$, the lowest value $(41 \%)$ being reached for high temperature treated carbons $\left(>1500^{\circ} \mathrm{C}\right)$. No clear correlation could be established between the electrode porosity and the tapped density. This could be understood by the dependence of the tapped density on several interplaying parameters, including the porosity (open, closed and inter-grain) and the morphology (particle shape and size). The compact carbon electrodes could deliver a high volumetric capacity of $\sim 300 \mathrm{~mA} \mathrm{~h} \mathrm{~cm}{ }^{-3}$. Such performance was achieved by combining low electrode porosity, low interlayer space, and low specific surface area as emphasized by comparison with several other lab-made and commercial hard carbons. Moreover, these carbon spheres revealed an initial Coulombic efficiency of $92 \%$, which is among the highest value reported for hard carbon. This could be correlated in large extent with the low values of the specific surface area of ultra-micropores $(<0.7 \mathrm{~nm})$, and further to the low amount of active sites and oxygen-containing functional groups. Several valuable property-performance correlations could be established, allowing for predicting the behavior of hard carbons in the Na-ion half-cells and full-cells.
\end{abstract}




\section{Introduction}

In recent years, increased attention has been paid to Na-ion batteries (NIBs), a cheaper, safer and long-lasting alternative to Li-ion batteries (LIBs). This is very attractive, especially for power applications and grid energy storage. ${ }^{1}$ Despite thorough research into negative electrodes, their electrochemical performance remains one of the main limiting factors for the full-cell development. Therefore, further in-depth studies are still required to design anode materials possessing optimal properties to reach better performance. Hard carbon is considered the state-of-art material for sodium ion batteries. It is preferred over other materials due to numerous advantages including a complex non-graphitizable structure that combines open/closed porosity with amorphous/pseudo-graphitic nano-domains, favorable for Na-ion storage. The precursors are cheap, green and abundant, and the synthesis procedure is straightforward (simple pyrolysis is often used), while the capacity delivered $\left(\sim 300 \mathrm{~mA} \mathrm{~h} \mathrm{~g}^{-1}\right)$ approaches that of graphite in lithium ion batteries $\left(372 \mathrm{~mA} \mathrm{~h} \mathrm{~g}^{-1}\right)$. The possibility of using a largy variety of precursors (raw biomasses, ${ }^{2-4}$ biopolymers $^{5-8}$ or synthetic polymers ${ }^{9-11}$ ) and of tuning the synthesis conditions has led to the preparation of a broad range of hard carbon materials with distinct properties and electrochemical performance. ${ }^{2,12,13}$ More specifically, in many reports, there is a general trend to introduce new types of precursors to obtain hard carbons. These materials sometimes deliver high performance, but the general roadmaps for material optimization to further improve their performance and/or their transition to full-cell tests are very scarce. It is worth mentioning that an overwhelming proportion of these studies are done in half-cells, which means that metallic $\mathrm{Na}$ is used as both counter and reference electrode. Such utilization of metallic sodium induces important disadvantages, such as large resistance and polarization, which might result in an inaccurate capacity evaluation (since the low voltage plateau of the hard carbon host is no longer available) ${ }^{14}$ and poor cyclability.

In a broader context, it can be noted a great lack of studies and knowledge regarding the requirements of hard carbon for up-scaling purposes. It must be considered that for anode materials to be commercially relevant, their derived-coated electrodes must possess high volumetric energy density and long cycle stability. ${ }^{15,16}$ Thus, the active carbon material should present some important features, such as high tapped density and low specific surface area, to obtain compact electrodes with a low initial irreversible capacity, and to minimize the losses of sodium in the first charge/discharge cycle owing to the formation of the solid electrolyte interphase (SEI) layer. Moreover, the high anode irreversibility during the first cycle imposes 
a higher mass of cathode material to compensate for the initial capacity loss. This translates into a higher weight of the overall cell which is detrimental to the specific energy density.

The tapped density is defined as the ratio of the mass to the volume occupied by a powder after tapping for a certain period of time. Referring to batteries, the tapped density is related to the mass of the active material (hard carbon anode herein) that can fit a default space. A low tapped density comes with inconveniences, such as thicker electrodes, so a lower volumetric capacity. Moreover, a large inter-particle space (low tapped density) and high electrode porosity results in high inter-particle resistance, limiting the electron transport within the active material, as well as between the later one and the current collector. ${ }^{16}$ Therefore, tapped density appears as a critical parameter to be considered for battery assembly, and high values are required for optimal performance. Surprisingly, there are only very few reports dealing with this topic in the literature and, to the best of our knowledge, only one work reported the tapped density values of some hard carbons. ${ }^{17}$ However, the correlation between the HCs key properties and tapped density was not addressed in a systematic way.

As mentioned earlier, energy density is among the most important characteristics of an energy storage system. Besides tapped density, another essential feature that must be optimized for cell energy density improvement is the electrode porosity. The manufacturing process of the electrodes ends with the compaction or calendering step (see Scheme 1), where the electrode coated on the current collector is passed through a gap (using two rolls working in opposite directions) with a smaller size than the electrode thickness.

Consequently, the overall porosity of the electrode (mixture active material/binder/additive) is reduced, resulting in a thinner and more compact electrode that further leads to volumetric capacity improvement. ${ }^{18-20}$ Thus, this stage is crucial in the preparation of high-performance electrodes. However, at the laboratory scale tests, this step is seldom or not at all achieved. Moreover, from a fundamental point of view, the carbon main properties impacting the electrode porosity are not yet known and no studies in this direction are available so far, to the best of our knowledge.

In the present paper, we prepared hard carbon spheres with controlled particle size and various properties, which were tuned by the pyrolysis temperature. Then, a systematic study was performed to correlate the hard carbon characteristics with the tapped density, the electrode porosity after calendering and the electrochemical performance (volumetric reversible capacity 
and $\mathrm{iCE}$ ). It was found that the decrease of several carbon properties (porosity, graphitic interlayer space, oxygen functionalities and defects) could lead to an increase of the tapped density and a decrease of the electrode porosity. Moreover, the initial Coulombic efficiency and the volumetric capacity could be significantly increased. The use of supplementary lab-made and commercial carbons allowed to highligh several in-depth correlations, such as the impact of closed pores on the tapped density. Moreover, the particle shape and size were identified to contribute to the electrode porosity. Thus, the optimal hard carbon properties leading to high volumetric capacity and high initial Coulombic efficiency could be revealed. The findings reported below provide a precious roadmap for lab-to-industrial transition of hard carbon anodes for Na-ion batteries up-scaling.

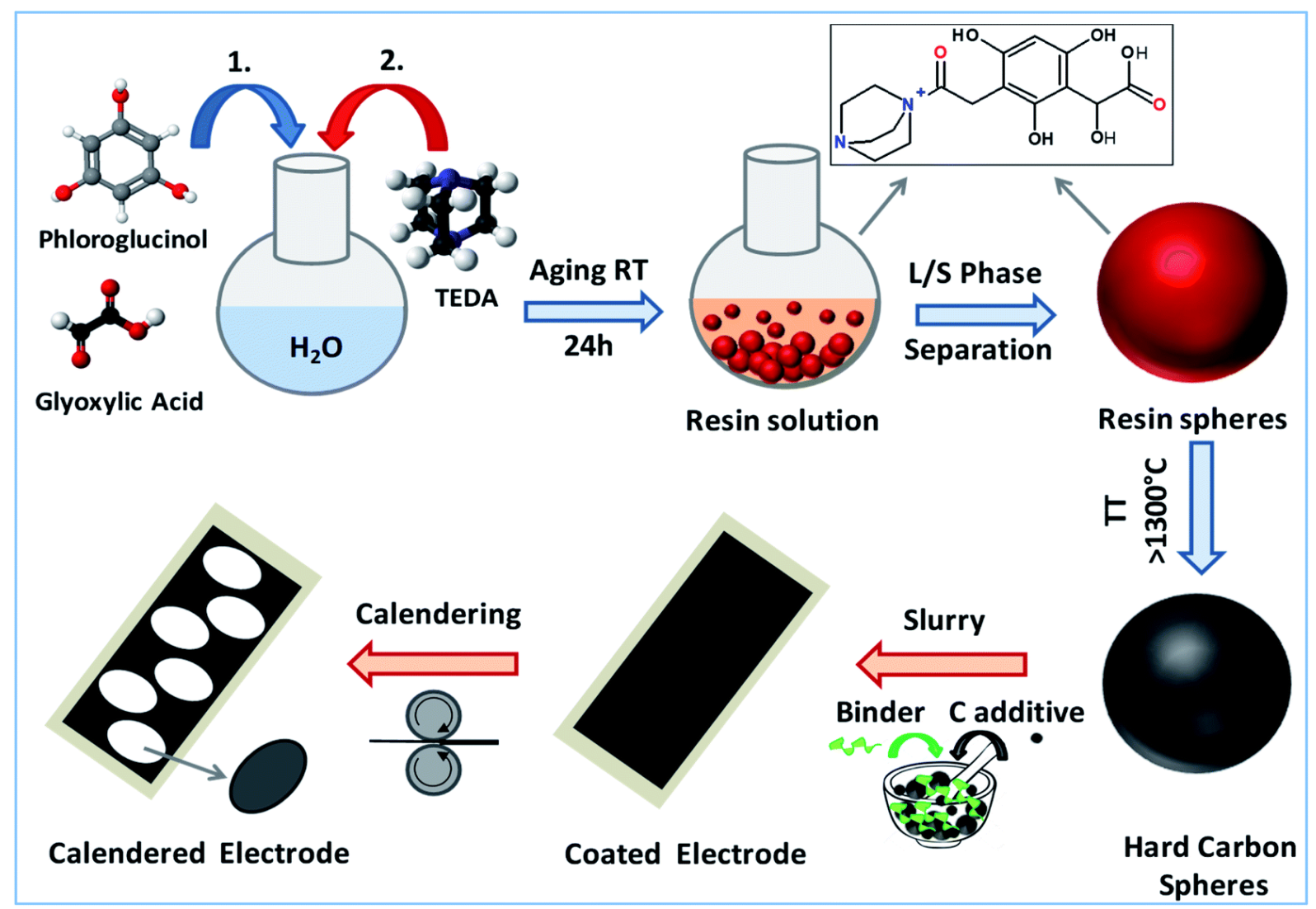

Scheme 1 Schematic representation of the hard carbon sphere synthesis procedure and electrode manufacturing steps. 


\section{Results and discussion}

A sustainable and scalable synthesis procedure is proposed to prepare the hard carbon spheres, which lies on the precipitation-polymerization of phloroglucinol-glyoxylic acid monomers in the presence of triethylenediamine (TEDA) cross-linker. Different from most of the works reporting carbon spheres using hydrothermal carbonization (high temperature and pressure), ${ }^{21-}$ ${ }^{23}$ the reactions herein occur at room temperature and ambient pressure, using water as solvent. After aging for $24 \mathrm{~h}$, phenolic resin polymer spheres are formed according to a mechanism described elsewhere. ${ }^{24}$ The as-formed polymer spheres were recovered and thermally annealed in the $1300-1600{ }^{\circ} \mathrm{C}$ temperature range under an inert atmosphere, ${ }^{25}$ as presented in Scheme 1. Additional information can be found in the Experimental section. The resulting hard carbon materials (denoted HCST, where $T$ is the annealing temperature) preserved the individual spherical morphology and, for such reason, do not require a grinding step. This advantage is of high importance for the large-scale production of hard carbon since this additional step is complex and costly from an industrial point view, and may also modify the material surface (i.e., porosity/surface chemistry increase ${ }^{26}$ ). Spherical morphology is interesting for anode electrode preparation, as well. Besides the high degree of compaction, spherical particles can be an efficient option to prepare homogenous electrodes with improved mass transport by decreasing the ion transport path, ${ }^{27}$ and to buffer the volume expansion due to sodiated compound formation. ${ }^{28}$ These benefits motivated our choice for this type of morphology to be explored as anodes for $\mathrm{Na}$-ion batteries.

Morphology analyses by SEM technique (Fig. 1a) showed individual and well-defined spheres with a grain-size distribution (Fig. 1b), revealing a mean particle size of 3-4 $\mu \mathrm{m}$ and larger particles up to $12 \mu \mathrm{m}$. No significant differences could be observed between the four samples (Fig. S1, ESI), meaning that the morphology size/shape is maintained up to $1600{ }^{\circ} \mathrm{C}$, as shown in Fig. $1 \mathrm{~b}$ as well. However, it should be noted that the distribution corresponding to larger particles $(5-10 \mu \mathrm{m})$ is not exactly identical, and small differences can be seen among the samples. The particle size distribution found can be favorable for a compact arrangement of particles since the smaller carbon spheres might fit between the free spaces created by the larger spheres. ${ }^{29}$ As the tapped density is emphasized for materials later on, the volume distribution determined based on the particle diameter and frequency was evaluated as well (Fig. S2, ESI). It was found that the particles with a larger diameter, i.e., $7-8 \mu \mathrm{m}$, give an intense volume distribution although they are small in number. 

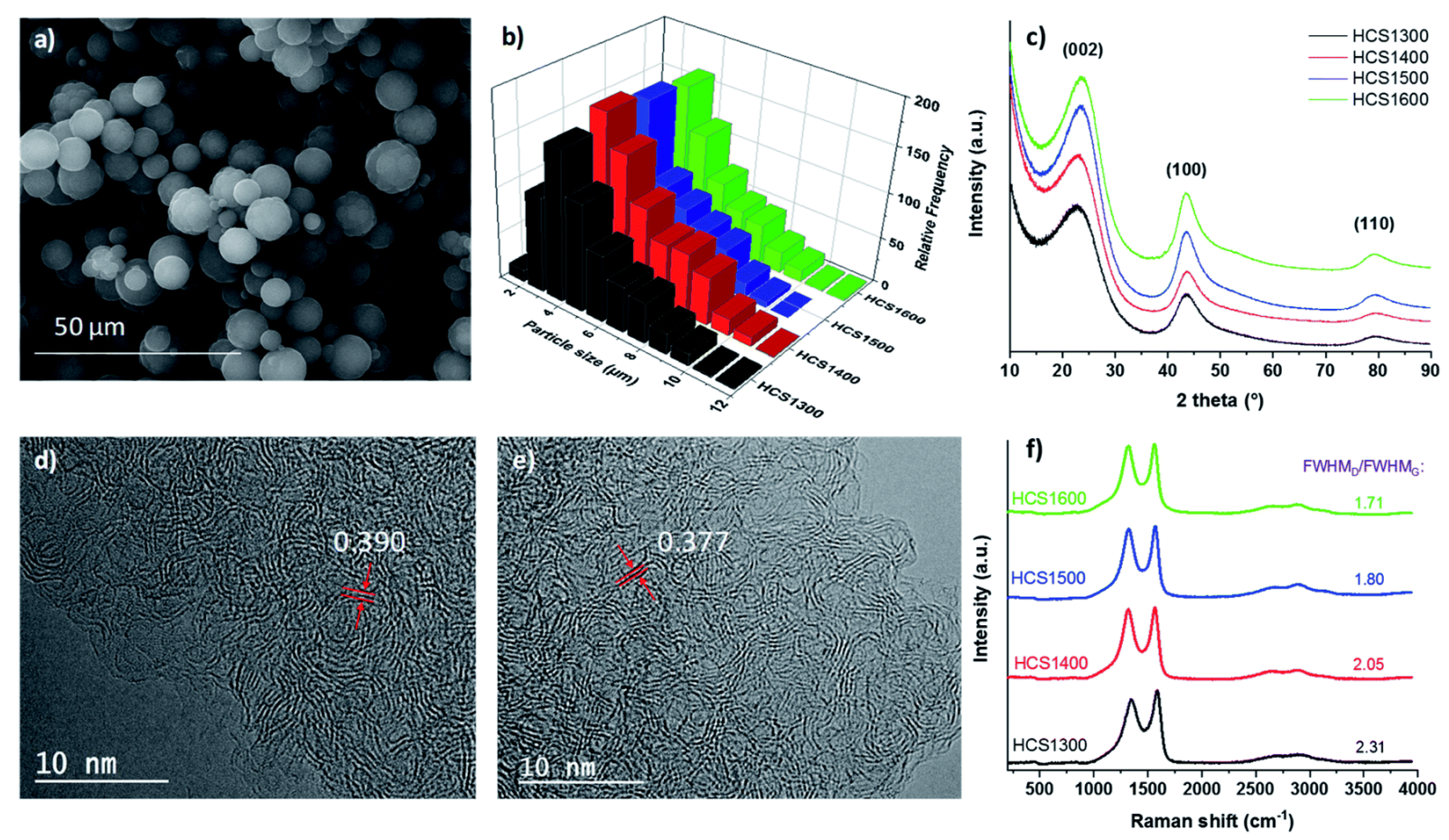

Fig. 1 Hard carbon materials characterization: (a) SEM image of HCS1300; (b) HC's mean grain size distribution based on SEM images; (c) XRD diffractograms, HR-TEM images of HCS1300 (d) and HCS1600 (e), and Raman spectra of the HC materials (f).

The materials structure was evaluated by several complementary analyses. The XRD patterns of the hard carbon materials (Fig. 1c) reveal the presence of several characteristic peaks. The (002) diffraction planes $\left(2\right.$ theta $^{\circ} \approx 23^{\circ}$ ) show a small shift towards higher 2 theta angles with the increase of the temperature from 1300 to $1600{ }^{\circ} \mathrm{C}$. As a result, the interplanar distance $\left(d_{002}\right)$ calculated using Bragg's law decreases from 3.90 to $3.77 \AA$ (Table 1). Such high $d_{002}$ values, along with the broad (002) peaks, point out that the obtained carbon materials have a rather disordered-like structure, which is typical of hard carbon materials. ${ }^{30}$

Besides the (002) diffraction plane, the other two hard carbon "footprints" are present as well: (100) at approximately $44^{\circ}$ and (110) at $\sim 80^{\circ}$. Based on the Scherrer equation and using the (002) and (100) XRD peaks, the crystallite height $\left(L_{\mathrm{c}}\right)$ along the $c$-axis and the crystallite width ( $\left.L_{\mathrm{a}}\right)$ along the $a$-axis were determined, as summed up in Table S1, ESI. One can see that the crystallite height values are inversely proportional to the $d$-spacing found. Thus, the HCS1600 sample has the highest $L_{\mathrm{c}}$ value $(12.3 \AA)$, indicating that more graphene layers $(\sim 2-3)$ are stacked together. A similar trend was found for the crystallite width, and the values increased from $34.1 \AA$ for HCS1300 to $39.6 \AA$ for HCS1600. This is also in line with the evolution of the FWHM of both (002) and (100), and which decreases with temperature from 8.02 ${ }^{\circ}$ (HCS1300) 
to $7.25^{\circ}(\mathrm{HCS} 1600)$ for the 002 peak, and from $5.07^{\circ}$ to $4.36^{\circ}$ in the case of the 100 peak. Such evolution indicates that the lateral crystallite size extends with the increase of the annealing temperature, which could be helpful for sodium ion storage, as reported elsewhere. ${ }^{31}$ Thus, the increase in both $L_{\mathrm{a}}$ and $L_{\mathrm{c}}$ parameters is sign of an improvement of the graphitization degree with temperature.

Table 1 Hard carbon characteristics, including particle size and shape (R-random and $S$ spherical morphology), graphite interlayer distance $\left(\mathrm{d}_{002}\right)$, specific surface area (SSA), active surface area (ASA), oxygen-based surface groups (CO $\left.O_{\mathrm{x}}\right)$, tapped density, He density and electrode porosity.

\begin{tabular}{|c|c|c|c|c|c|c|c|c|c|}
\hline $\begin{array}{c}\text { Sample } \\
\text { name }\end{array}$ & $\begin{array}{l}\text { Part. } \\
\text { size } \\
\mu \mathrm{m}\end{array}$ & $\underset{\AA}{d_{002}}$ & $\begin{array}{c}\mathbf{N}_{2} \\
\mathrm{SSA} \\
\mathbf{m}^{2} \mathbf{g}^{-1} \\
\end{array}$ & $\begin{array}{c}\mathrm{CO}_{2} \\
\mathrm{SSA} \\
\mathbf{m}^{2} \mathrm{~g}^{-1} \\
\end{array}$ & $\begin{array}{c}\text { ASA } \\
\mathbf{m}^{2} \mathbf{g}^{-1}\end{array}$ & $\begin{array}{c}\mathrm{CO}_{x} \\
\mathrm{mmol}^{-1} \\
\mathrm{~g}^{-1}\end{array}$ & $\begin{array}{l}\text { Tapped } \\
\text { density } \\
\mathrm{g} \mathrm{cm}^{-3}\end{array}$ & $\begin{array}{c}\text { He } \\
\text { density } \\
\mathrm{g} \mathrm{cm}^{-3}\end{array}$ & $\begin{array}{c}\text { Electrode } \\
\text { porosity } \\
\% \\
\end{array}$ \\
\hline HCS1300 & $\begin{array}{l}3-4 \\
(\mathrm{~S})\end{array}$ & 3.90 & 2.7 & 60.0 & 11.9 & 0.360 & 0.71 & 2.11 & 62 \\
\hline HCS1400 & $\begin{array}{l}3-5 \\
(\mathrm{~S})\end{array}$ & 3.87 & 7.0 & 20.5 & 3.3 & 0.110 & 0.74 & 2.16 & 54 \\
\hline HCS1500 & $\begin{array}{l}3-4 \\
(\mathrm{~S})\end{array}$ & 3.80 & 3.5 & 6.5 & 1.2 & 0.046 & 0.84 & 1.87 & 46 \\
\hline HCS 1600 & $\begin{array}{l}3-4 \\
(\mathrm{~S})\end{array}$ & 3.77 & 6.0 & 9.0 & 1.3 & 0.044 & 0.72 & 1.63 & 41 \\
\hline$P A C 2^{a}$ & $\begin{array}{c}5-10 \\
(R)\end{array}$ & 3.75 & 3.8 & 3.6 & 6.4 & 0.070 & 0.96 & 1.95 & 46 \\
\hline PR1400 & $\begin{array}{l}>2 \\
\text { (R) }\end{array}$ & 3.90 & 24 & 188.5 & 3.5 & 0.24 & 1.0 & 2.12 & 64 \\
\hline TCA1400 & $\begin{array}{l}2.2 \\
(\mathrm{~S})\end{array}$ & 3.80 & 23 & 343 & 21.8 & 0.55 & 0.70 & 1.95 & 47 \\
\hline TCA1300 & $\begin{array}{l}2.2 \\
(\mathrm{~S}) \\
\end{array}$ & 4.00 & 104 & 425 & 11.8 & 0.26 & 0.33 & 2.28 & 72 \\
\hline НАB 1400 & $\begin{array}{l}0.4 \\
(\mathrm{~S}) \\
\end{array}$ & 4.00 & 25 & 136.5 & 9.9 & 0.26 & 0.35 & 2.22 & 64 \\
\hline
\end{tabular}

The altering of local clusters of straight or curved graphite layers with more disordered amorphous-like zones can be seen for all samples by HR-TEM, which is typical for the disordered-like hard carbon materials. As an example, the microscopic images obtained for HCS1300 and HCS1600 are shown in Fig. 1d and e (all images are provided in Fig. S3, ESI). It can be observed that the temperature rise leads to more organized graphene layers, which is in accordance with the $L_{\mathrm{c}}$ values that increased from $10.8 \AA$ to $12.3 \AA$. Moreover, on the HCS1600 material, some spaces between the graphene layers can be seen and associated with 
closed pore formation, which can be visualized in Fig. S4, ESI. More local insights on the carbon structure were provided by Raman analysis, as presented in Fig. 1f. All hard carbons showed two intense and sharp peaks at around $1340 \mathrm{~cm}^{-1}$ and $1590 \mathrm{~cm}^{-1}$, corresponding to the defect-induced D-band and the crystalline graphite $\mathrm{G}$ band, respectively. At higher Raman shift values (2500-3200 $\mathrm{cm}^{-1}$ ), supplementary peaks of broad shape and low intensity could also be observed. The area covered by the $\mathrm{D}$ and $\mathrm{G}$ peaks is often used to quantify the disorder degree $^{21,22,32}$ by determining the areal ratio, $I_{\mathrm{D}} / I_{\mathrm{G}}$. However, the $I_{\mathrm{D}} / I_{\mathrm{G}}$ ratio is recommended for graphitic materials, thus leading to less accurate results for the hard carbon materials. The values found here increase with the temperature from 1.25 to 1.66 (Table S1, ESI†), which is an opposite trend than expected for materials with improved structural degree. Thus, for the disordered carbons, other parameters must be considered, i.e., peak intensity and broadness, reason why FWHM (Full Width at Half Maximum) values were determined (inset Fig. 1f). These values confirmed a high disorder degree that decreases with increasing temperature, from 2.31 (HCS1300) to 1.71 (HCS1600), which is in line with the XRD and TEM results. Therefore, based on the XRD, TEM and Raman analyses, it can be concluded that the graphitization degree within the materials increases with the pyrolysis temperature.

The textural properties of the hard carbon materials were evaluated by $\mathrm{N}_{2}$ adsorptiondesorption and $\mathrm{CO}_{2}$ adsorption isotherms (Fig. 2a). Type II $\mathrm{N}_{2}$ isotherms were obtained, which is a characteristic of non-porous materials. As a result, all samples have a BET specific surface area that is lower than $10 \mathrm{~m}^{2} \mathrm{~g}^{-1}$ (see Table 1). Although the optimal SSA values for sodium ion applications are not clearly established, such low values are reported to be favorable for $\mathrm{Na}^{+}$ storage $^{13,33}$ and particularly to prevent electrolyte decomposition, which may cause significant irreversible capacity. The pore size distribution was determined from the $\mathrm{N}_{2}$ adsorption results, and revealed mainly micropores $(<2 \mathrm{~nm})$, along with some small mesopores of a size centered at around $3 \mathrm{~nm}$.

Additional insight on the materials texture was obtained by $\mathrm{CO}_{2}$ gas, known to provide faster diffusion kinetics and better accessibility to narrower pores. The $\mathrm{CO}_{2}$ adsorption isotherms (inset, Fig. 2a) revealed higher $\mathrm{CO}_{2}$ adsorbed volume than $\mathrm{N}_{2}$ volume, which points out clear evidence of ultra-microporosity $(<0.7 \mathrm{~nm})$, as seen in the pore size distribution provided in the inset of Fig. 2b. In consequence, the SSAs determined based on $\mathrm{CO}_{2}$ adsorption are higher: 60, 20.5, 6.5 and $9 \mathrm{~m}^{2} \mathrm{~g}^{-1}$ for HCS1300, HCS1400, HCS1500 and HCS1600, respectively (Table 1). Such results suggest that a well-developed network of pores is present in the materials. 
However, due to the very narrow size/shape, they cannot be accessed by $\mathrm{N}_{2}$ gas, thus making the $\mathrm{CO}_{2}$ adsorption technique a necessity to better characterize the hard carbon texture. Such pores of small sizes are expected to be favorable for sodium ion transportation during the charging - discharging process, but they can also contribute to the irreversible capacity. For the moment, their impact on Na-storage is not well known. It is important to mention that the increase of the pyrolysis temperature leads to a gradual decrease of SSA until $1500{ }^{\circ} \mathrm{C}$. Conversely, at $1600{ }^{\circ} \mathrm{C}$, the surface area slightly increases.
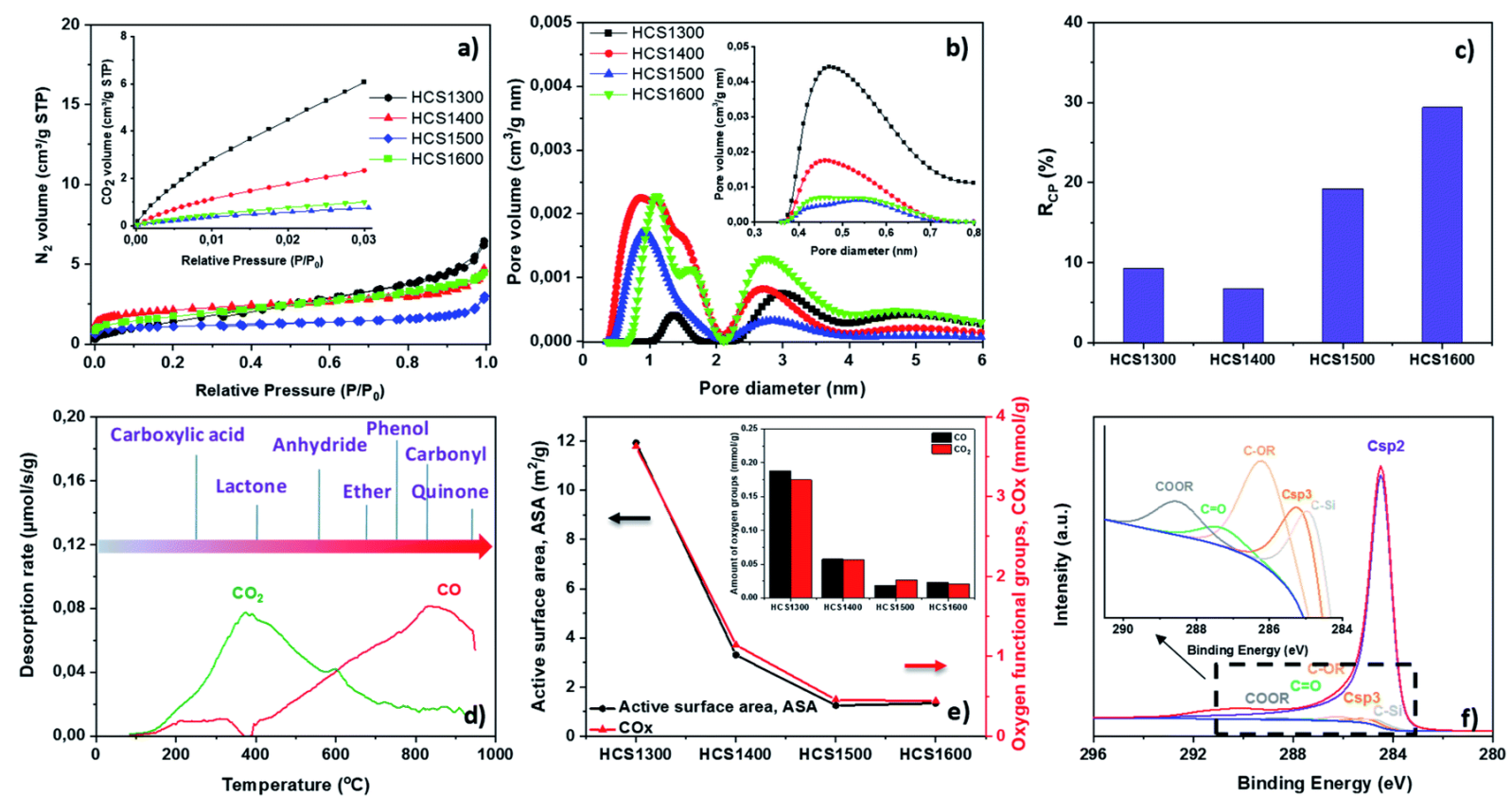

Fig. 2 (a) Hard carbon $\mathrm{N}_{2}$ adsorption-desorption isotherms and $\mathrm{CO}_{2}$ adsorption isotherms (inset); (b) pore size distribution based on $\mathrm{N}_{2}$ and $\mathrm{CO}_{2}$ (inset) adsorption results; (c) evolution of the ratio of closed pore volume $\left(\mathrm{R}_{C P}\right) ;(d) \mathrm{CO}_{2}$ and $C O$ TPD-MS desorption curves for HCS1300, along with the types of oxygen-based functional groups leading to the $\mathrm{CO}$ and $\mathrm{CO}_{2}$ release; (e) active surface area and the amount of oxygen-based functional groups $\left(\mathrm{CO}+\mathrm{CO}_{2}\right.$, inset) evolution; ( $f$ ) XPS C1s high-resolution deconvoluted spectra of HCS1300.

A similar trend is observed for the $\mathrm{N}_{2}$ adsorption results, although the very low values at the limit of the detection threshold make it difficult to conclude. Such an increase has been observed in the literature before, and is listed as an indicator for the formation of a closed porosity due to structural reorganization. ${ }^{34}$ Although the closed porosity is not supposed to be accessed by the electrolyte, it can participate Na-ion storage according to some works, as will be discussed later on. It is also expected to have an important contribution on the material density and electrode compaction properties, as illustrated in Scheme 2. A high level of closed pores means 
a higher volume of material, thus negatively affecting the tapped density. Likewise, the open porosity (inter- and intra-particle porosity) may impact the active material tapped density and more importantly, the electrode porosity. The electrode porosity is therefore impacted by all the existing spaces between the particles, and within the particles themselves. Thus, the calendering step becomes essential to obtain compact electrodes with reduced thickness (volume), to improve the conductivity - as the voids between the particles increase the diffusion path- and to increase the volumetric capacity.

Therefore, the volume of the closed porosity was calculated based on the materials. He density and the open pore volume determined by nitrogen adsorption (details are given in the Experimental part). It could be observed (Table S2, ESI) that the ratio of the closed pores $\left(R_{\mathrm{CP}}\right)$ is rather similar $(\sim 7-9 \%)$ between $1300{ }^{\circ} \mathrm{C}$ and $1400{ }^{\circ} \mathrm{C}$. It then increases significantly, reaching $30 \%$ of the total volume for HCS1600 (Fig. 2c). Li et al. also reported that the volume of closed pores increases with temperature, while using a slightly different calculation formula that considers only the pycnometric density. ${ }^{35}$ Regarding the ratio of open pores $\left(R_{\mathrm{OP}}\right)$, the percentage is very low for all samples (below 2\%). The occurrence of the closed pores seems to be temperature-induced: the open porosity vanishes between $1300{ }^{\circ} \mathrm{C}$ and $1500{ }^{\circ} \mathrm{C}(\mathrm{dec} r e a s e$ of SSA, by both $\mathrm{N}_{2}$ and $\mathrm{CO}_{2}$, bellow $10 \mathrm{~m}^{2} \mathrm{~g}^{-1}$ ) to leave the place to closed porosity. Reported SAXS analyses in the literature ${ }^{36,37}$ pointed out an increase in the closed pore size with the temperature, usually in the range of micropores $(<2 \mathrm{~nm})$. However, quantification of the closed pore volume cannot be achieved.

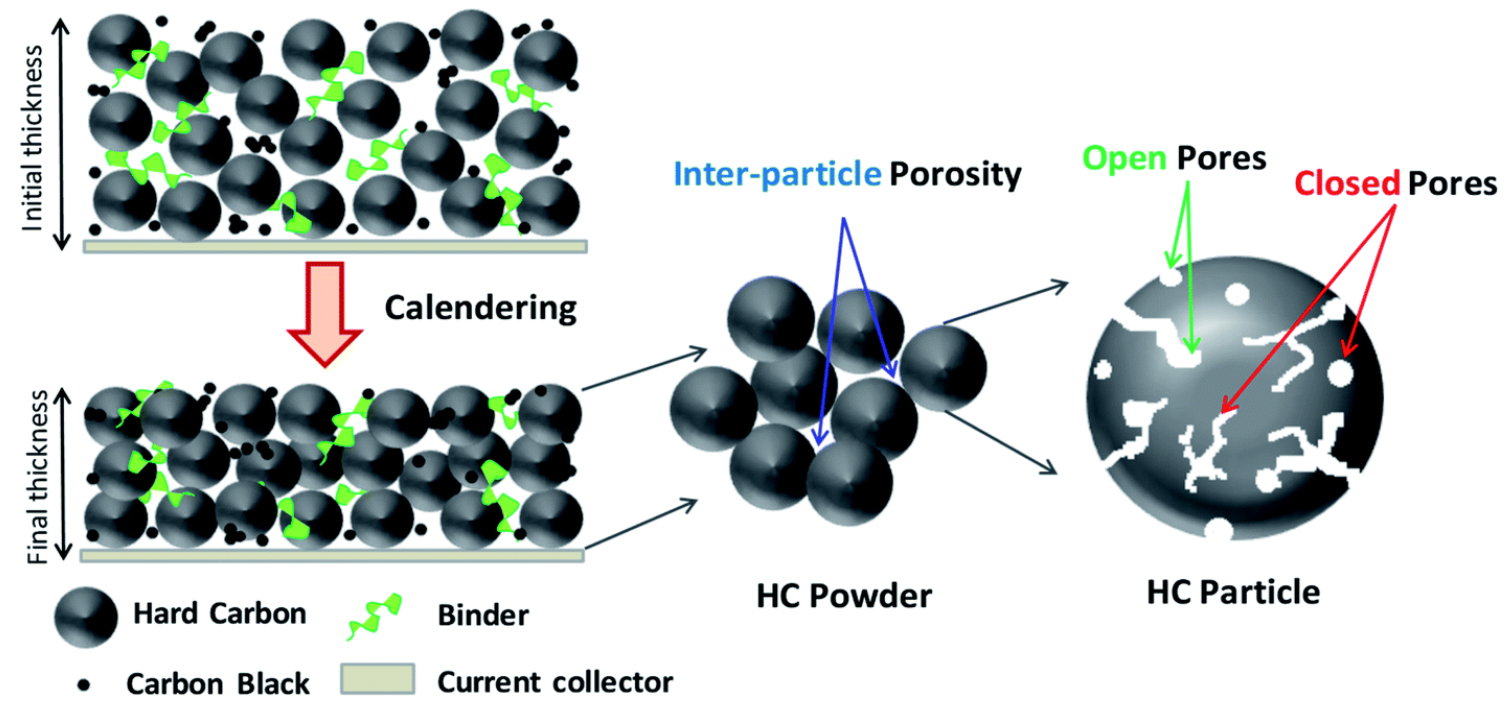

Scheme 2 Different types of porosity present on the hard carbon structure, and their influence on the electrode thickness during calendering. 
TPD-MS (temperature-programmed desorption coupled with mass spectrometry) was used to determine the nature of the oxygen-based functional groups and their amount in the whole bulk materials. In such an analysis, the carbon is heated under vacuum and the oxygen functional groups are decomposed in $\mathrm{CO}$ and $\mathrm{CO}_{2}$ gaseous species. As an example, the results obtained for HCS1300 are shown in Fig. 2d, and the details of the entire HCSs series are shown in Fig. S5. $\uparrow$ The corresponding oxygen-containing functional groups are identified based on their decomposition temperature, according to literature. ${ }^{38}$ In the case of $\mathrm{HCS} 1300$, the $\mathrm{CO}_{2}$ desorption profile shows a broad peak in the temperature range of $200-700{ }^{\circ} \mathrm{C}$, indicating that a large family of acidic functional groups decomposes, i.e., carboxyl and lactone groups. ${ }^{9,39} \mathrm{At}$ higher temperatures of $>400{ }^{\circ} \mathrm{C}$, the anhydride decomposition produces $\mathrm{CO}_{2}$ and $\mathrm{CO}$. The $\mathrm{CO}$ desorption usually starts at temperatures higher than $400{ }^{\circ} \mathrm{C}$ as a result of the decomposition of phenols, ethers, quinones or/and carbonyl groups, the last two being very stable. When comparing the four samples (Fig. 2e, Table 1), it can be seen that the total amount of decomposed oxygen-based functional groups $\left(\mathrm{CO}_{x}\right)$ decreases with the increase of the annealing temperature from $0.36 \mathrm{mmol} \mathrm{g}^{-1}$ down to $0.044 \mathrm{mmol} \mathrm{g}^{-1}$ for HCS1300 and HCS1600, respectively. The $\mathrm{CO}$ and $\mathrm{CO}_{2}$ repartition show similar trends (inset of Fig. 2e).

XPS was also used to provide additional information on the surface chemistry of the materials. As an example, HCS1300 was analyzed, and the C1s high-resolution deconvoluted spectra are presented in Fig. 2f. The results showed an $\mathrm{O}$ content of 3.1 at $\%$ along with a high percentage of carbon (96.1 at\%). XPS analysis is a surface technique, while TPD-MS analyzes the bulk sample, thus, the two techniques are complementary, as observed previously. ${ }^{40}$ Both techniques revealed the presence of surface oxygen functional groups, whose concentration decreases with increasing pyrolysis temperature. Even if the functional groups could have an important role on the storage mechanism of sodium ions ${ }^{17,41,42}$ by favoring electrode wetting with electrolyte, at the same time, they can be involved in irreversible reactions if the amount is too high. In addition, the decrease of the at $\%$ of $\mathrm{O}$ with temperature is favorable for Na storage owing to the larger carbon (\%) amount in the materials composition.

In addition to surface functionality, hard carbon materials present structural defects (also known as active sites) involved in the storage mechanism of the $\mathrm{Na}$ ions, which can be quantified as the active surface area (ASA) with the help of TPD-MS. This is the only technique allowing for the quantitative evaluation of the edge defects (stacking faults, dislocation, atom vacancies). As an example, Fig. S5c and d (ESI) shows the details of the active surface area experiments 
for the HCS1400 material. Importantly, the experimental and calculated pressures overlap (Fig. $\mathrm{S} 5 \mathrm{c} \dagger)$, which denotes that the released gases during heating are the same as the calibrated ones, and no additional gases are desorbed. Fig. S5d, ESI reveals the evolution of the calibrated gases vs. temperature. $\mathrm{CO}$ is desorbed in higher amounts (large and intense peak) than the $\mathrm{CO}_{2}$ groups. A similar behavior was observed for the other samples. In terms of ASA $\left(\mathrm{m}^{2} \mathrm{~g}^{-1}\right)$, the HCS1300 material has the highest value (i.e., $11.9 \mathrm{~m}^{2} \mathrm{~g}^{-1}$ ). This was expected considering the larger amount of functional groups and a more defective structure (Table 1 and Fig. 1). For HCS1400, the ASA decreases significantly to $3.3 \mathrm{~m}^{2} \mathrm{~g}^{-1}$, while for HCS1500 and HCS1600, similar values were observed (1.2 and $1.3 \mathrm{~m}^{2} \mathrm{~g}^{-1}$, respectively). This can be related to a higher internal structural organization, oxygen groups removal, and the decrease of the surface area at such high temperatures. The evolution of both ASA and $\mathrm{CO}_{x}$ groups with the temperature follows the same trend with a monotonous decrease down to $1500{ }^{\circ} \mathrm{C}$, followed by a plateau, as illustrated in Fig. 2e. A similar trend was observed in our previous works on hard carbons derived from cellulose ${ }^{33}$ and PAN (polyacrylonitrile) fibers, ${ }^{11}$ although the values were precursor dependent. The one obtained for hard carbon spheres are rather comparable to the cellulose HC, while the PAN-derived HCs values are much lower.

Fig. 3a summarizes the change of the key characteristics of the HCS materials (SSA, ASA, CO and $d_{002}$ ) with the pyrolysis temperature. Except for the $\mathrm{N}_{2}$ SSA, which shows low values with steady evolution, all other parameters decrease with the increase of the temperature up to 1500 ${ }^{\circ} \mathrm{C}$. Between $1500{ }^{\circ} \mathrm{C}$ and $1600{ }^{\circ} \mathrm{C}$, the $\mathrm{CO}_{2}$ SSA slightly increases, while the $\mathrm{CO}_{x}$ content and ASA values stay constant. Such an increase of the $\mathrm{CO}_{2}$ SSA could be linked to the carbon structural reorganization at such high temperature, which leads to an increase of the closed porosity formed, as discussed above. As for the internal organization, it increases with temperature, as suggested by the continuous decreased evolution of $d_{002}$ values.

In order to highlight the $\mathrm{HC}$ features, the as-prepared materials were compared with a commercial hard carbon (PAC2) used in Na-ion battery prototypes. The physico-chemical properties of PAC2 HC (Table 1) were found to be rather close to that of the HCS1500 and HCS1600 materials, with the main difference occurring in the morphology, which is randomlike in the case of PAC2. As a first step, the tapped density was determined for HCS1300 and compared to PAC2 commercial carbon. The impact of the HC mass was evaluated by using a small batch of $1 \mathrm{~g} v s$. a larger batch of $10 \mathrm{~g}$. It is worth mentioning that the synthesis of carbon spheres (1 g vs. $10 \mathrm{~g}$ batch) was reproducible, as can be observed in Fig. S6 (ESI). 

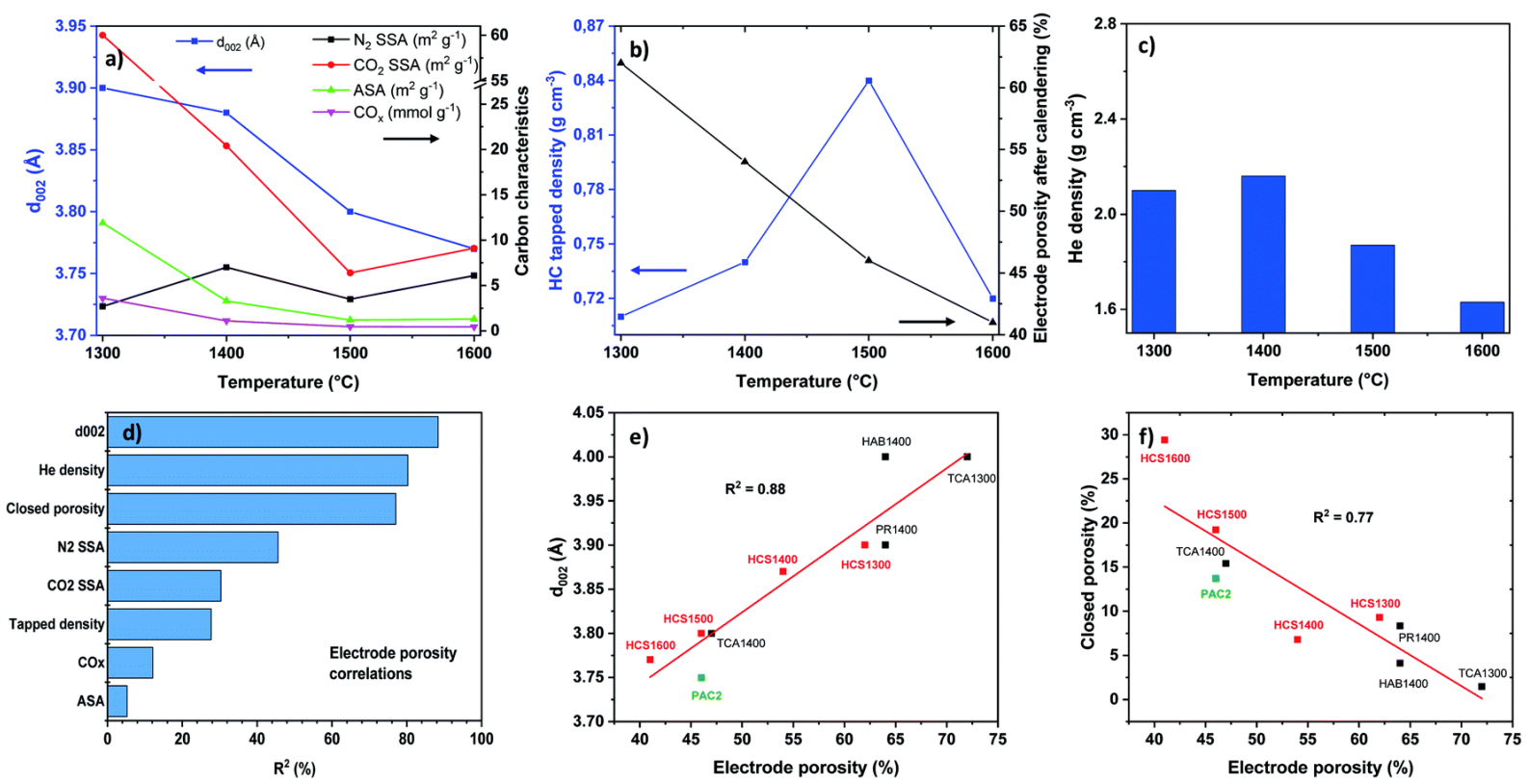

Fig. 3 (a) Hard carbon characteristics evolution as a function of the pyrolysis temperature (COx values were multiplied by 10 to clearly see their evolution). (b) Correlation between HCS tapped density and electrode porosity after calendering vs. pyrolysis temperature. (c) He density evolution with pyrolysis temperature. (d) Evolution of the electrode porosity (\%) as a function of the hard carbon characteristics given by the $\mathrm{R}^{2}$ coefficient of determination. Correlation between the electrode porosity vs. the interlayer space, $\mathrm{d}_{002}(e)$ and closed porosity $(f)$, along with the linear fit and the $\mathrm{R}^{2}$ determination factor.

The evolution of the materials tapped density and their volume as a function of the number of taps was monitored (Fig. S7). The commercial carbon exhibits a higher tapped density than HCS 1300 (0.96 vs. $\left.0.71 \mathrm{~g} \mathrm{~cm}^{-3}\right)$. The morphology, which may induce differences in the packing of particles, can be at the origin of higher found value. However, the lower ultramicroporosity (pores $<0.7 \mathrm{~nm}$ ), the low content of structural defects, and then the lower amount of functional groups (different $\mathrm{C}-\mathrm{C}$ interactions) may also contribute to some extent to the observed results. When the mass was increased to $10 \mathrm{~g}$, the tapped density of PAC2 and HCS1300 remained rather constant (Fig. S7). Therefore, higher loadings do not affect the tapped density, which is favorable for up-scaling applications.

Secondly, the influence of the HCSs annealing temperature on the tapped density was further investigated. Fig. 3b shows that the tapped density increased steeply from $0.71 \mathrm{~g} \mathrm{~cm}^{-3}$ for HCS 1300 to $0.84 \mathrm{~g} \mathrm{~cm}^{-3}$ for HCS1500. However, when the temperature is further increased to $1600{ }^{\circ} \mathrm{C}(\mathrm{HCS} 1600)$, the tapped density diminished significantly to $0.72 \mathrm{~g} \mathrm{~cm}^{-3}$, probably due 
to some internal structural organization. Interestingly, an important drop was also observed for the He density when the sample was treated at $1600{ }^{\circ} \mathrm{C}$ (Fig. 3c), as a result of the presence of the closed porosity (30\%). This may justify the significant decrease in the material density, as underlined recently in another work. ${ }^{35}$

At this point, one can argue that there is a higher tapped density value found for HCS1500 since the material has a high percentage of closed pores and a lower He density than HCS1400, for example. Here, the physico-chemical characteristics of the materials must be taken into account. All features (i.e., the interlayer space, the functional groups that increase the distance between particles, the amount of defects and the specific surface area) are higher for HCS1400 when compared to HCS1500. Thus, they might be responsible for the lower tapped density found for the HCS1400 sample. Moreover, although similar, the spheres volume distribution (Fig. S2) is not exactly the same. The volume ratio of large particles $v s$. small particles is higher for HCS1400 and thus more free spaces may remain between the carbon grains, leading to a higher volume and finally to a lower tapped density.

Therefore, by controlling the thermal treatment temperature up to $1500{ }^{\circ} \mathrm{C}$, the material tapped density could be improved. However, above this temperature, it was no longer possible. This trend may depend on the precursor type, the synthesis method used for conversion into hard carbon, the particle size and the morphology among other parameters. Thus, it is not possible to extrapolate to other $\mathrm{HC}$ materials: this threshold temperature is expected to be more or less different. Given that the hard carbon. He density and closed porosity are precursor-dependent, as already pointed out in the literature,${ }^{43}$ the tapped density may vary accordingly. Even though it was possible to increase the tapped density up to $0.84 \mathrm{~g} \mathrm{~cm}^{-3}$ (HCS1500), we could not reach the tapped density of PAC2 $\left(0.96 \mathrm{~g} \mathrm{~cm}^{-3}\right)$. At this point, considering that most of the characteristics are similar between the two materials, the morphology was thought to be responsible for the observed difference. While the HCS materials have a spherical morphology with particle size predominantly around $3.5 \mu \mathrm{m}$ and some larger particles (up to $12 \mu \mathrm{m}$ ), the PAC2 commercial material has a random morphology with a size ranging between 5 and $10 \mu \mathrm{m}$ (see Fig. 4a). Therefore, this may lead to a different organization of the particles. Irisarri et al. reported very different tapped density values for random or fiber-like cellulose-derived hard carbons. ${ }^{17}$ Based on these observations, it appears that the tapped density depends on several carbon properties, i.e., structure, texture, morphology and surface chemistry. Thus, it is significantly important to discriminate the most impacting ones among them. 

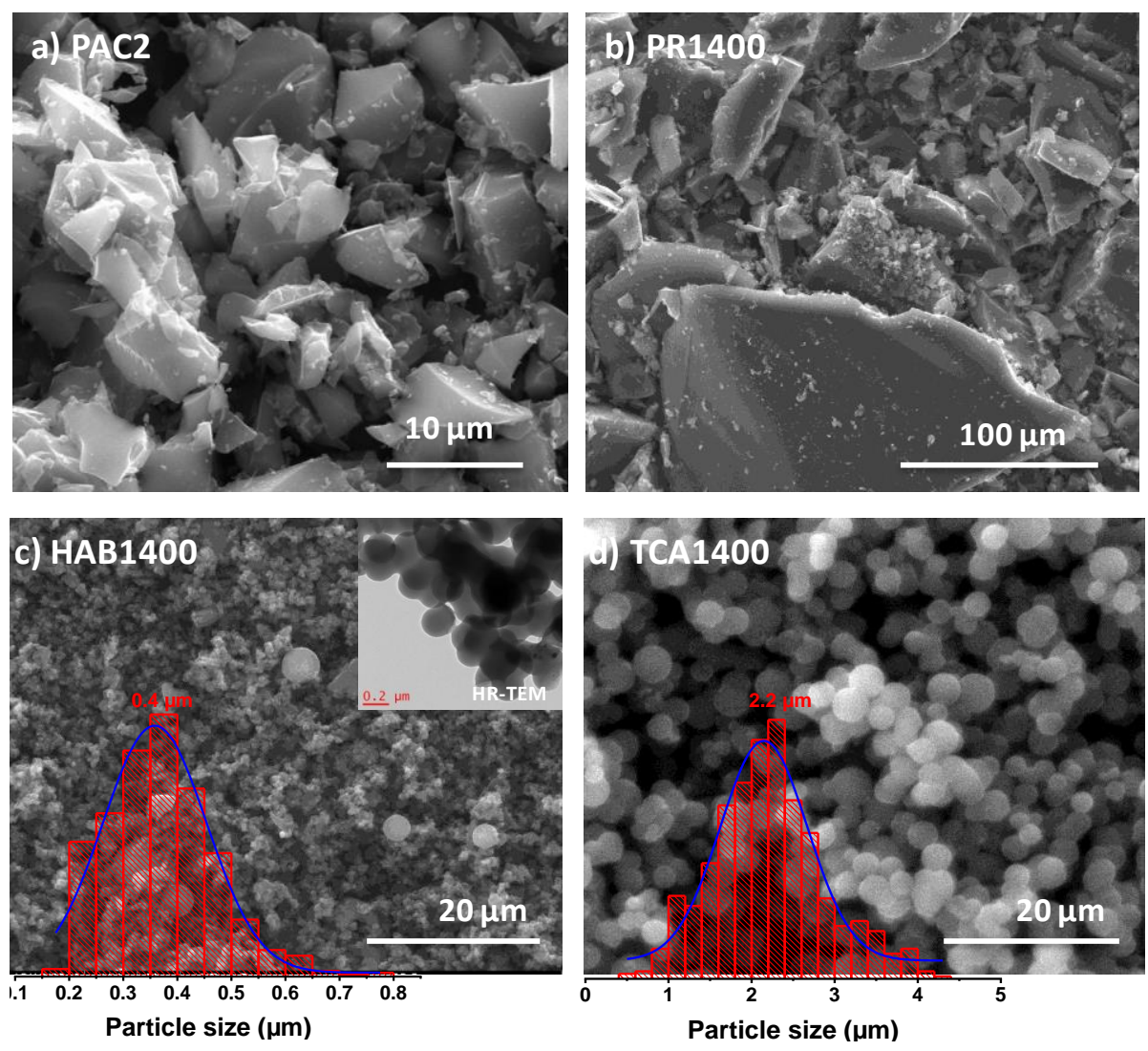

Fig. 4 SEM images of different HC materials with random (a and b) and spherical morphology (c and d).

To gain further insight and to provide a more general view in this purpose, a series of hard carbon materials were prepared accordingly to the protocols provided in the ESI. $\uparrow$ Their characteristics were assessed in a similar manner as those for the HCS series, as shown in Fig. S8 to S10 in the ESI $\uparrow$ and resumed in Table 1. The HAB1400 hard carbon sample with spherical morphology (Fig. 4c), but very small particles size $(0.4 \mu \mathrm{m})$ and low SSA $\left(18 \mathrm{~m}^{2} \mathrm{~g}^{-1}\right)$, possesses a tapped density of only $0.28 \mathrm{~g} \mathrm{~cm}^{-3}$. Conversely, the carbon spheres (TCA1300) with comparable grain size to the HCS series (2.2 vs. $3.4 \mu \mathrm{m})$, but higher SSA $\left(104 v s . \sim 10 \mathrm{~m}^{2} \mathrm{~g}^{-1}\right)$, show a similar low tapped density of $0.33 \mathrm{~g} \mathrm{~cm}^{-3}$. The small particle size of the HAB1400 sample results in a large inter-particle porosity, leading to lower tapped density, while the high opened porosity of the TCA1300 sample also triggered a low tapped density. ${ }^{17}$ When the pyrolysis temperature was increased to $1400{ }^{\circ} \mathrm{C}$ instead of $1300{ }^{\circ} \mathrm{C}$ for the TCA material, a drastic decrease of the specific surface area was observed from $104 \mathrm{~m}^{2} \mathrm{~g}^{-1}$ to $23 \mathrm{~m}^{2} \mathrm{~g}^{-1}$, resulting in a 2-times increased tapped density (from $0.33 \mathrm{~g} \mathrm{~cm}^{-3}$ to $0.70 \mathrm{~g} \mathrm{~cm}^{-3}$ ), thus demonstrating the important role of the open porosity. In summary, these carefully selected examples suggest that a low open and inter-grain porosity must be favored to achieve higher tapped density. 
On the other hand, when using a hard carbon presenting a random morphology (PR1400) and large particle size $(>10 \mu \mathrm{m})^{8}$, a very high tapped density of $1.0 \mathrm{~g} \mathrm{~cm}^{-3}$ was measured (Fig. 4, Table 1). This value is slightly higher than that of the commercial PAC2 material $\left(0.96 \mathrm{~g} \mathrm{~cm}^{-3}\right)$, which also presents random shape and large particle size. Those results suggest that the random morphology is another key characteristic to increase the material packing arrangement and the tapped density.

The electrode porosity is one of the last parameters that can be optimized before assembling the cell. The electrode (open) porosity drives the volumetric capacity (compaction improvement) and the irreversible capacity at the first cycle. This is because the porosity (total surface area) favors the solid electrolyte interphase layer formation, as it was already been reported. ${ }^{12}$ The electrode porosity after calendering constantly decreases with the annealing temperature for the HCS series (Fig. 3b), from 62\% (HCS1300) to 41\% (HCS1600). The continuous decrease in the values of the physico-chemical characteristics along with the particle size distribution (which is slightly different) could be accounted for the decrease in the electrode porosity.

It is worth mentioning that the PAC2 material leads to electrodes with $46 \%$ porosity after calendering. Thus, we could reach and exceed this threshold for HCS1500 and HCS1600, despite the lower tapped density of HCS vs. PAC2. It should not be overlooked that for the electrode porosity calculation, the pycnometric $(\mathrm{He})$ density is also involved (as detailed in the Experimental section). Thus, this parameter plays an important role. The He density of carbon indeed depends on several parameters, such as the opened porosity, closed porosity, inter-grain porosity, structure and arrangement of particles (Scheme 2). However, the limitation of such technique must be considered, in particular when dealing with materials having opened and closed porosity, and the comparison must stay for similar hard carbon materials (including similar particle size and morphology). If one considers, for example, graphite (no porosity, limited defects) the pycnometric density (herein, also the true density) is high, i.e., $2.3 \mathrm{~g} \mathrm{~cm}^{-3}$; however, it leads to low electrode porosity $(\sim 25-40 \%) .{ }^{41,42}$ For such graphite electrodes, $~ 30 \%$ electrode porosity is considered as ideal for Li-ion batteries. It is interesting to see if for Na-ion batteries using hard carbon as electrode, the same electrode density could be reached.

Additionally, if one considers the evolution of the electrode porosity versus the tapped density for the additional hard carbons (Table 1), it can be seen that both HAB1400 and TCA1300 with low tapped density $\left(0.28\right.$ and $\left.0.33 \mathrm{~g} \mathrm{~cm}^{-3}\right)$ exhibit the highest electrode porosity (64 and $72 \%$, respectively). The low tapped density can be explained by the high inter-particle porosity of 
HAB1400 and the high opened porosity of TCA1300. Besides, similar high electrode porosity ( $64 \%)$ was obtained for HCS1300 and PR1400 materials with high tapped density (0.7 and $1.0 \mathrm{~g} \mathrm{~cm}^{-3}$ ). Therefore, additional parameters (structure, defects, chemistry) impact the electrode porosity. This is emphasized by the rest of the materials exhibiting lower electrode porosity (below 50\%). HCS1600 shows the lowest electrode porosity ( 41\%). Although it has a lower tapped density than PAC2 (i.e., $0.71 v s .0 .96 \mathrm{~g} \mathrm{~cm}^{-3}$ ), which was explained before as a consequence of closed porosity, the difference in morphology type and the particle size, HCS1600 presents a lower surface area (-micro and -ultra micropores), a lower amount of functional groups and defects and a smaller interlayer distance than PAC2.

Furthermore, we attempt to systematically correlate the electrode porosity evolution with hard carbon characteristics by determining the $R^{2}$ coefficient. More precisely, the electrode porosity evolution was represented as a function of each carbon property and the obtained data were fitted with a linear function, which gave the determination factor $R^{2}$. The detailed fitted data are presented in the ESI, Fig. S11, while Fig. 3d gathers the $R^{2}$ values (in \%) for all carbon parameters. Very interestingly, it can be seen that the interlayer distance $\left(d_{002}\right)$ is the driving factor on the electrode porosity, with an $88 \%$ influence. Thus, the electrode porosity decreases with $d_{002}$ (Fig. 3e). Furthermore, the electrode porosity shows a rather opposite correlation with the closed porosity (Fig. 3f) and decreases with increasing closed porosity (temperature enhancement). This is somehow expected, considering the opposite evolution of the closed porosity $v s$. $d_{002}$. The other carbon properties were found to have less impact $\left(R^{2}<50 \%\right)$ on controlling the electrode porosity. In summary, it could be highlighted that a low electrode porosity can be reached if the carbon internal structure is more organized ( $d_{002}$ is low).

All materials were electrochemically tested, and their performance compared with that of the commercial carbon (PAC2). Fig. 5a shows the initial Coulombic efficiency (iCE) obtained for the four HCSs, PAC2 and PR1400 to better highlight the results. 

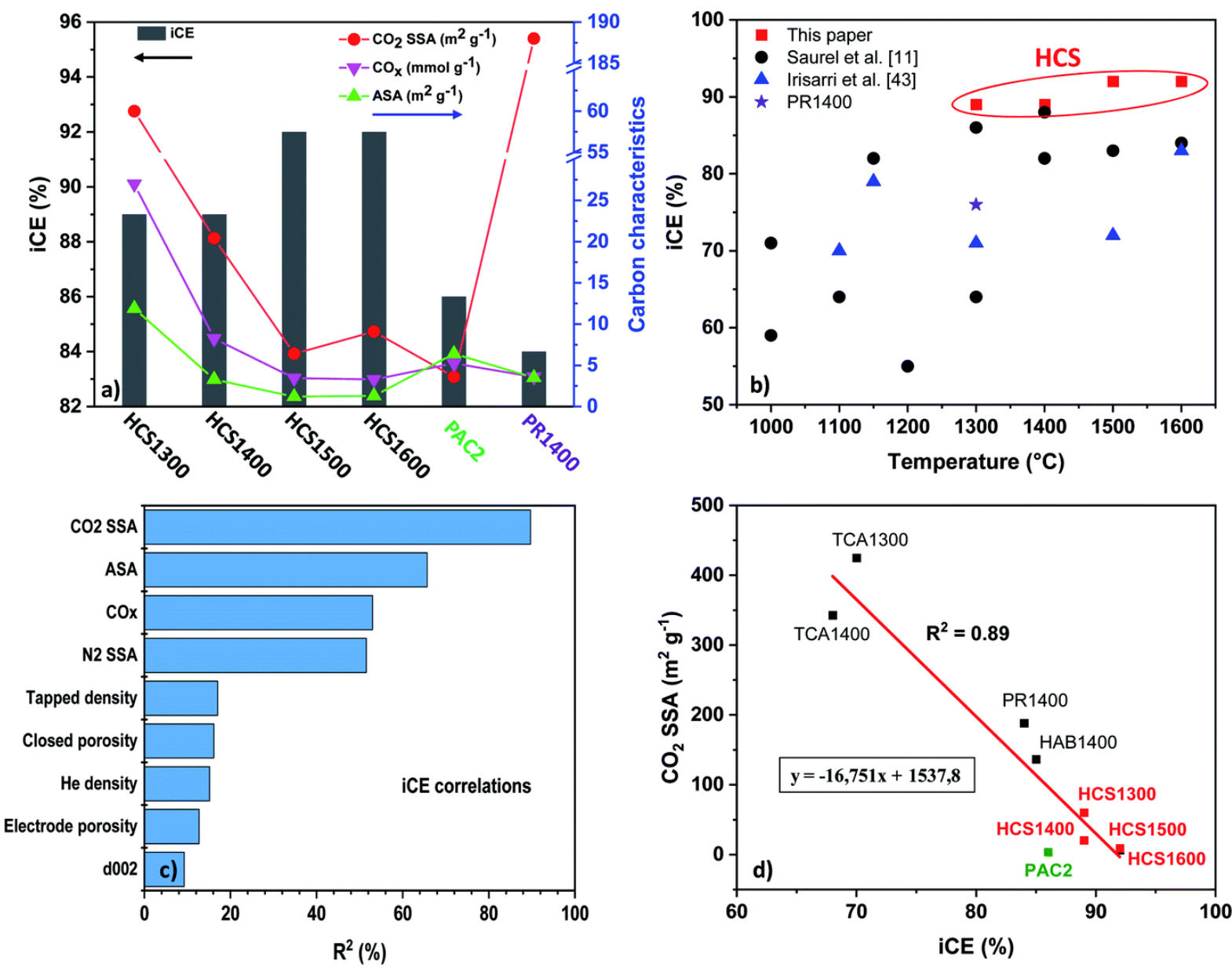

Fig. 5 (a) Evolution of the initial Coulombic efficiency (iCE) vs. different carbon characteristics $\left(\mathrm{CO}_{2}\right.$ specific surface area, $\mathrm{CO}_{\mathrm{x}}$ groups and $\mathrm{ASA}$ ). $\mathrm{CO}_{\mathrm{x}}$ values were multiplied by 15 to clearly see their evolution. (b) Comparison between the iCE of the HCs obtained in this work (HCS) vs. reported ones in the literature. ${ }^{11,43}$ (c) Evolution of iCE (\%) as a function of hard carbon properties given by the $\mathrm{R}^{2}$ coefficient of determination. $(d)$ The linear fitting curve of hard carbon iCE and specific surface area determined by $\mathrm{CO}_{2}$ adsorption ( $\left.\mathrm{CO}_{2} \mathrm{SSA}\right)$, along with the $\mathrm{R}^{2}$ factor and the fitting equation.

The iCE is the direct result of the initial irreversible capacity $\left(C_{\text {irrev }}\right)$ which, from the literature, is known to be closely related to SSA, surface chemistry and structural defects. ${ }^{13,33,44}$ First, one can see a general trend through HCS materials, i.e., iCE increases with temperature and reaches 92\% for both HCS1500 and HCS1600 (Fig. 5a). To the best of our knowledge, such values are among the highest iCE reported in the literature. ${ }^{12,45}$

Next, we aimed to see if the evolution of the iCE with temperature is directly proportional to other physico-chemical parameters. It was first attempted to correlate the specific surface area determined by both $\mathrm{N}_{2}$ and $\mathrm{CO}_{2}$ adsorption with iCE. As the $\mathrm{N}_{2} \mathrm{SSA}$ is well known to impact 
the irreversible capacity (and thus iCE) by favoring the SEI formation, we have less knowledge about the $\mathrm{CO}_{2}$ surface area. In the present case, the $\mathrm{N}_{2}$ surface area is small for all HCSs materials (below $10 \mathrm{~m}^{2} \mathrm{~g}^{-1}$ ), which normally ensures the materials with low and similar irreversible capacity. However, when increasing the pyrolysis temperature, $C_{\text {irrev }}$ decreases, while the $\mathrm{N}_{2}$ SSA is rather constant; thus, no clear trend is observed. This suggests that additional parameters are responsible for $C_{\text {irrev }}$ improvement.

The $\mathrm{CO}_{2}$ SSA can be one impacting parameter since this surface, given by very narrow pores, is decreasing with the temperature until $1500{ }^{\circ} \mathrm{C}$, and then a small increase is seen. At the same time, diminishing the amount of functional groups and structural defects also contributes to the decrease of irreversibility in the first cycle due to their direct interaction with Na-ions. The importance of the $\mathrm{CO}_{2}$ SSA on $C_{\text {irrev }}$ is well illustrated for PR1400 where, the high value (188 $\mathrm{m}^{2} \mathrm{~g}^{-1}$ ) leads to significant $C_{\text {irrev }}$ and thus lower iCE of $84 \%$, despite the limited amount of surface groups. Now, if we compare the materials that delivered the highest iCE (92\%), namely the HCS1500 and HCS1600, with PAC2 commercial carbon ( $86 \% \mathrm{iCE})$, their porosity $\left(\mathrm{N}_{2}\right.$ and $\mathrm{CO}_{2} \mathrm{SSA}$ ) and their $d_{002}$-space are rather similar. However, the amount of oxygen functional groups and the active surface area (amount of defects) are two to three times lower for HCSs than for PAC2 (see Table 1). Therefore, these findings strongly suggest that, besides the specific surface area decrease, the decrease in the oxygen functional groups and defects are key factors that improve the iCE, likewise. Moreover, the obtained results here for the HCSs are compared to a series of $\mathrm{HC}$ materials reported in a few literature review papers. ${ }^{12,45}$ Since the pyrolysis temperature used to prepare PAC2 is unknown, the material could not be shown. From Fig. 5b, it is clear that the iCE values achieved by the hard carbon spheres (89-92\%) are higher than both the commercial carbon $(86 \%)$ and the other materials previously published, that show iCE values mainly below $80 \%$. Such high values found for the herein reported materials are very interesting in the context of full-cells testing since the low iCE (thus high irreversible capacity) requires more cathode material to compensate the initial loss, and therefore, higher weight and cost per cell.

To have a more general view of the key parameters impacting the iCE, the later one was expressed as a function of several carbon properties via the $R^{2}$ coefficient, as depicted in Fig. $5 \mathrm{c}$. It is worth noting that the most important parameter impacting the iCE was found to be the specific surface area determined by $\mathrm{CO}_{2}$ adsorption, thus, the corresponding surface of ultramicropores. A rather linear trend was obtained between the iCE and the SSA $\mathrm{CO}_{2}$, and a high 
coefficient of determination $R^{2}=0.89$ (Fig. $5 \mathrm{~d}$ ) could be revealed. To the best of our knowledge, this is the first time that such correlation is observed and this is of great importance. In particular, the $\mathrm{CO}_{2}$ probe molecule is marginally used in the literature to assess the hard carbon porosity. Nitrogen is the preferred gas; however, it can be seen that although the $\mathrm{N}_{2} \mathrm{SSA}$ impacts the $\operatorname{iCE}\left(R^{2}=0.51\right.$, Fig. S12), it correlates less than $\mathrm{CO}_{2} \mathrm{SSA}\left(R^{2}=0.89\right)$. In addition to porosity, the amount of active sites (ASA) and the oxygen-based functional groups $\left(\mathrm{CO}_{x}\right)$ (Fig. 5c) have an important influence on the evolution of iCE, as well $\left(R^{2}=0.66\right.$ for ASA and $R^{2}=0.53$ for $\left.\mathrm{CO}_{x}\right)$. The other parameters, which are linked more with the carbon structure $(e . g$. $d_{002}$, density) have only a limited impact on the $\operatorname{iCE}\left(R^{2}<0.2\right)$. The detailed fitted data are presented in the ESI, Fig. S12.

The normalized charge- discharge galvanostatic curves of various hard carbon materials are presented in Fig. 6a. The four profiles are very similar, and only small differences could be noticed between the samples. The small shoulder observed between 1.0 and $0.8 \mathrm{~V}$, and related to electrolyte decomposition and SEI formation, is more pronounced for the sample treated at $1300{ }^{\circ} \mathrm{C}$. This can be associated with the higher amount of oxygen functional groups and structural defects (Table 1), as discussed above. Furthermore, the sloping potential region (above $\sim 0.1 \mathrm{~V}$ ) has the highest contribution in capacity for HCS1300, and decreases with the increase of temperature, in agreement with other studies. ${ }^{46}$ Such trend may be correlated to the decrease of the open porosity, functional groups and defects observed between the samples (Table 1). This is consistent with recent studies on Na storage mechanisms suggesting that the sloping region is related to $\mathrm{Na}^{+}$adsorption into pores/defects and interaction with the surface functional groups, while the plateau region is linked to $\mathrm{Na}^{+}$intercalation between the graphene layers. ${ }^{33,40,44,47}$ Referring to the plateau region, it can be seen that the capacity gained below 0.1 $\mathrm{V}$ is enhanced with the increase of temperature from 1300 to $1600{ }^{\circ} \mathrm{C}$. This might be related to the increase of both $L_{\mathrm{c}}$ and $L_{\mathrm{a}}$ values (development of pseudo-graphitic regions) with temperature (Table S1), which might be favorable for Na storage as reported in the literature. ${ }^{28}$ As the closed porosity ratio augment as well with the temperature (Fig. 2), a contribution from Na-ion filling in the plateau region cannot be excluded. 

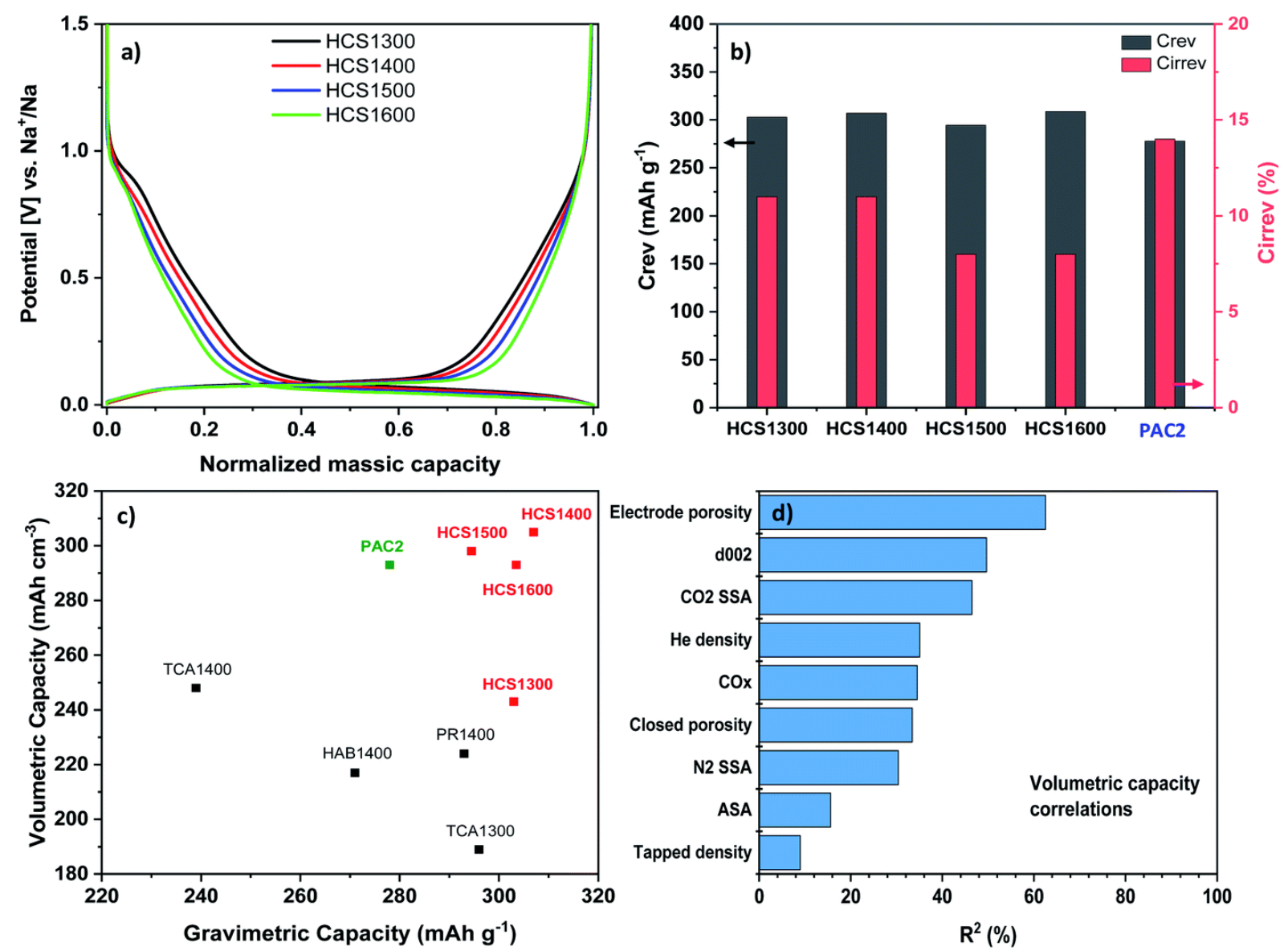

Fig. 6 (a) Normalized discharge-charge profiles of the HCS materials during the first charge/discharge cycle in half-cells. (b) First cycle reversible capacity and initial irreversible capacity of the HCSs and PAC2 commercial HC at C/50 rate. (c) First cycle gravimetric vs. volumetric capacities delivered by the HCSs and a series of hard carbon materials in half-cells. (d) Volumetric capacity correlations with hard carbon properties given by $\mathrm{R}^{2}$ coefficient of determination.

To provide additional insights on the sodium storage mechanism, the capacitive (non-diffusive) and diffusion-limited (bulk) contributions were studied. The HCS1500 material is discussed herein. A common approach implies the using of a power-law equation $\left(I=a v^{b}\right),{ }^{48}$ where $a$ and $b$ are adjustable parameters, $I$ is the current (A), and $v$ is the potential sweep rate $\left(\mathrm{mV} \mathrm{s}^{-1}\right)$. The $b$-value can be assessed by determining the slope of the linear fit of $\log (I) v s . \log (v)$ plot, while the intercept gives the $a$ value. Generally, $b$ values around 0.5 indicate a process controlled by the diffusion of $\mathrm{Na}$ into the graphene layers, while a value of 1.0 indicates a surface, capacitivelike process (adsorption of $\mathrm{Na}^{+}$into porosity or functional groups). Cyclic voltammetry (CV) measurements at different potential scan rates $\left(0.06-3.21 \mathrm{mV} \mathrm{s}^{-1}\right)$ were performed (Fig. 7a). 
The obtained $b$-value from the linear fit (Fig. $7 \mathrm{~b}$ ) is close to 0.5 , which indicates that the $\mathrm{Na}$ storage mechanism is mainly governed by diffusion processes.
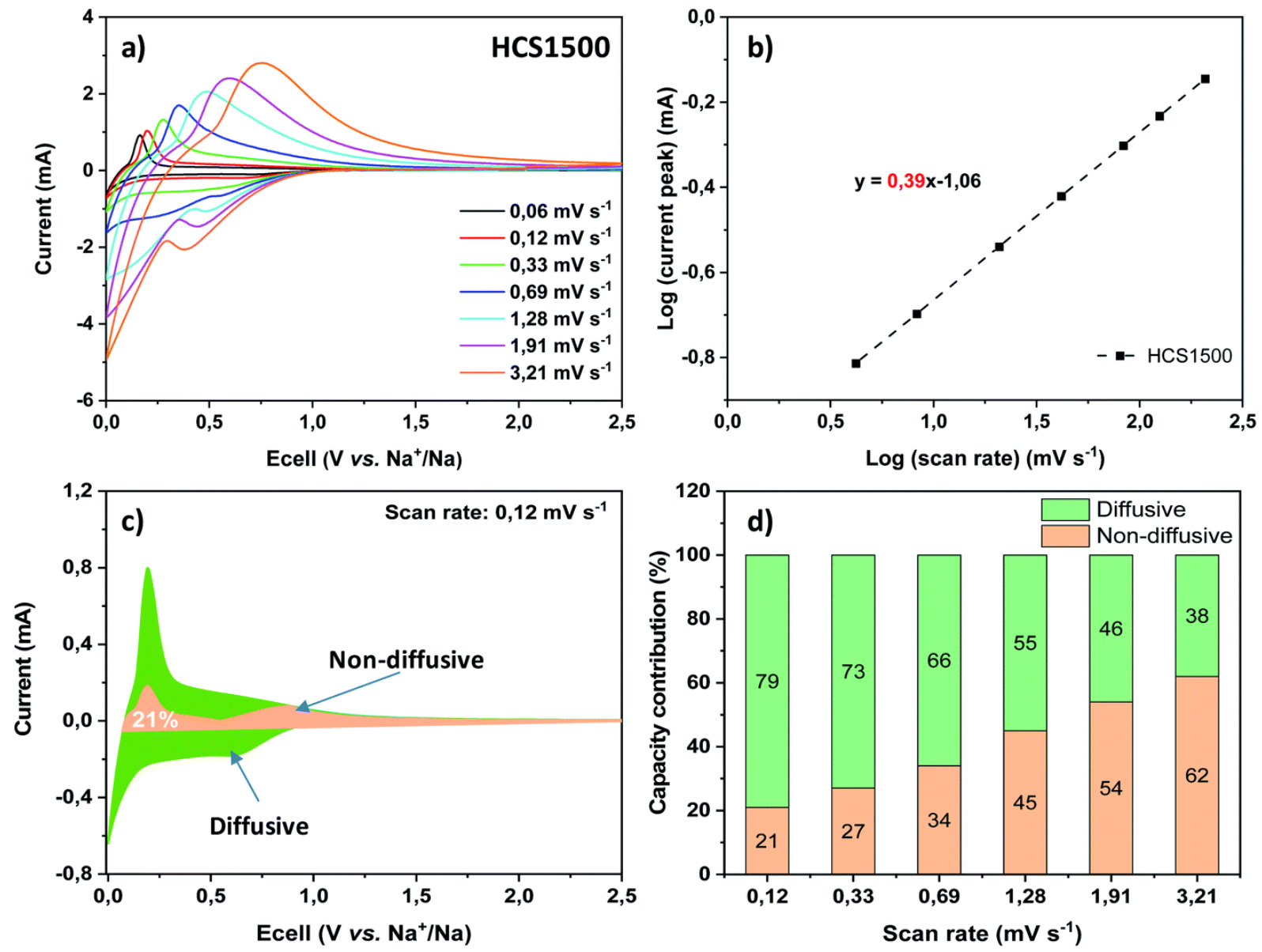

Fig. 7 (a) Cyclic voltammograms at different scan rates $\left(0.06-3.21 \mathrm{mV} \mathrm{s}^{-1}\right)$ between $0 \mathrm{~V}$ and $2.5 \mathrm{~V}$ vs. $\mathrm{Na}^{+} / \mathrm{Na}$ for the HCS1500 material. (b) The linear correlation between the current peak and the scan rate for HCS1500. (c) Capacitance contribution at a scan rate of $0.12 \mathrm{mV}$ $s^{-1}$ for HCS1500. (d) The diffusive and non-diffusive contribution at different scan rates of HCS1500.

Furthermore, by using the Dunn method, ${ }^{49}$ the diffusion-controlled process and the nondiffusion process were quantified for each scan rate based on the formula: $I(V)=k_{1} v+k_{2} v^{1 / 2}$ where $k_{1}$ and $k_{2}$ are constant values used to distinguish between diffusion and non-diffusive contributions, while " $v$ " is the scan rate. In Fig. 7c, an example is given for the obtained results at low scan rate $\left(0.12 \mathrm{mV} \mathrm{s}^{-1}\right)$. The above observations are confirmed since the diffusive contribution is predominant and counts for $79 \%$, whereas the capacitive one counts for only $21 \%$. However, with the scan rate increase, the latter contribution enhances and reaches $62 \%$ at 
a scan rate of $3.2 \mathrm{mV} \mathrm{s}^{-1}$, as illustrated in Fig. 7d. Similar results were obtained for HCS1400 and HCS1600 (Fig. S13, ESI).

When comparing the results of HCSs to PAC2, the hard carbon spheres have better reversible capacity (Fig. 6b), which exceeds $300 \mathrm{~mA} \mathrm{~h} \mathrm{~g}^{-1}$ (except HCS1500, which has a slightly lower value, i.e., $294 \mathrm{~mA} \mathrm{~h} \mathrm{~g}^{-1}$ ). More importantly, very low initial irreversible capacity, i.e., $8 \%$ for HCS 1500 and HCS1600 and $11 \%$ for HCS1300 and HCS1400, could be achieved. PAC2 delivers $278 \mathrm{~mA} \mathrm{~h} \mathrm{~g}^{-1}$ reversible capacity during the first cycle and an initial irreversible capacity of $14 \%$, which is higher than HCSs. Thus, all four HCS materials exhibit superior performance than commercial carbon. Such low values found for the initial irreversible capacity are very appealing in the context of full-cell battery testing. Moreover, the high delivered reversible capacity, along with the low electrode porosity found for some of the materials, is expected to lead to higher volumetric capacities

For a more general view, the relationship between the gravimetric and volumetric capacity for the five materials (HCS series and PCA2) is presented in Fig. 6c, along with the additional hard carbon materials discussed before (PR1400, HAB1400, TCA1300 and TCA1400). In terms of the volumetric capacity, it can be seen that HCS1300 has lower performance when compared to PAC2. The commercial carbon is more compact than HCS1300 (25\% denser), and the electrode porosity is significantly lower after calendering at 46\% (PAC2) vs. 62\% (HCS1300). Therefore, the capacity delivered $v s$. volume of the active material is higher for PAC2 (293 mA $\left.\mathrm{h} \mathrm{cm}^{-3}\right)$ than HCS1300 (243 $\left.\mathrm{mA} \mathrm{h} \mathrm{cm}^{-3}\right)$. However, with the annealing temperature increase, the HCS materials could deliver a volumetric capacity that is higher than that of the commercial carbon, as a consequence of the decrease of the electrode porosity (Table 1). Thus, $305 \mathrm{~mA} \mathrm{~h}$ $\mathrm{cm}^{-3}$ and $300 \mathrm{~mA} \mathrm{~h} \mathrm{~cm}{ }^{-3}$ were obtained for HCS1400 and HCS1500, respectively, whereas HCS1600 showed similar performance to PAC2, $293 \mathrm{~mA} \mathrm{~h} \mathrm{~cm}^{-3}$. It is worth noting that the volumetric capacity calculation takes into account both the electrode porosity and the pycnometric density (eqn (3) and (4)). Indeed, the reason why HCS1600 delivers a smaller volumetric capacity, despite a high gravimetric capacity and low electrode porosity, relies in its low pycnometric density. For the additional hard carbon materials presented in Fig. 6c (TCA1300, HAB1400, PR1400), a high gravimetric capacity but lower volumetric capacity vs. HCS materials was observed (i.e., below $230 \mathrm{~mA} \mathrm{~h} \mathrm{~cm}^{-3}$ ). This can be explained by a very large electrode porosity (between 64-72\%, Table 1). For a complete overview regarding the most important hard carbon properties affecting the volumetric capacity, Fig. 6d shows that beside the electrode porosity, which is somehow expected considering eqn (4) in the Experimental 
section, the carbon structure $\left(d_{002}\right)$ and the ultra-micro porosity $\left(\mathrm{CO}_{2} \mathrm{SSA}\right)$ are of prime importance. The other parameters may also have an impact on the volumetric capacity, but to a lesser extent. Therefore, a high volumetric capacity can be ensured by low values of both $d_{002}$ and specific surface area.

GITT potential profiles of the sodiation and desodiation of HC materials (HCS1400, HCS1500 and HCS1600) during the first cycle are shown in Fig. S14a, while the apparent diffusion coefficients were determined based on Fick's second law for both sodiation and desodiation process, and are presented in Fig. S14b and c. Overall, it can be seen that the diffusion coefficients are relatively constant (especially during the desodiation process) at different states of charge (between 0 and 100\%), and rather small fluctuations are observed when comparing the sloping region with the plateau region. During sodiation, however, some tendency can be observed in which the diffusion coefficient slightly decreases with the state of charge (SOC) from $-7.5 \mathrm{~cm}^{2}$ at $0 \% \mathrm{SOC}$ to $-9.5 \mathrm{~cm}^{2}$ at $70 \% \mathrm{SOC}$, corresponding to the plateau region. This could suggest that as the porosity/defect sites are gradually filled (sloping region), considering that is more difficult for sodium ions to overcome the energy barrier of the graphite nanocrystallite interlayer.

Moreover, electrochemical impedance spectroscopy measurements were performed on the same HC materials at different SOC during sodiation. The Nyquist plots (Fig. S15) show a diffusion-limited process in the low frequency region, two semicircles in the middle-frequency region originating from the charge transfer reactions at the electrode surface and SEI layer formation, and finally, a small curve that intersects the $x$-axis at high frequency, assigned to the cell inductance and ohmic resistance. The observed behavior among the materials revealed that the resistance at the electrode surface increases with the state of charge, and might be related to the SEI layer formation. The low-frequency tail shows a comparable behavior for the three materials, meaning that $\mathrm{Na}^{+}$diffusion is similar, in line with the GITT results that showed comparable diffusion coefficients.

Due to the optimal properties found, namely a low electrode porosity, low irreversibility and high gravimetric capacity, HCS1400 and HCS1500 could deliver very high volumetric capacities, along with the highest iCE (i.e., 92\%). Thus, they are very interesting options for further full-cell tests. HCS1500 was thus tested as anode in a full-cell, choice motivated by its high tapped/He density, low electrode porosity and low irreversible capacity in the first cycle. However, sodium metal is suitable only for lab-scale tests, but for real applications, Na metal 
is not a practical option due to its low melting point $\left(97.7^{\circ} \mathrm{C}\right)$ and its tendency to easily form dendrites. The NVPF $\left(\mathrm{Na}_{3} \mathrm{~V}_{2}\left(\mathrm{PO}_{4}\right)_{2} \mathrm{~F}_{3}\right)$, is the most common material used as a cathode for sodium ion batteries owing to its appropriate features, i.e., average potential of $3.95 \mathrm{~V}$ and theoretical capacity of $128 \mathrm{~mA} \mathrm{~h} \mathrm{~g}^{-1.50}$ It was used herein as counter electrode, with a mass ratio of 2.3:1 (NVPF:HCS1500) (details about the NVPF material preparation, its main characteristics and electrochemical performance $v s$. $\mathrm{Na}^{+}$can be found in ESI). The full-cell (Fig. 8a) delivers a specific capacity of $124 \mathrm{~mA} \mathrm{~h}^{-1}$ (NVPF) and an iCE of 86\%, corresponding to $17 \mathrm{~mA} \mathrm{~h} \mathrm{~g}^{-1}$ initial irreversible capacity when cycled at $\mathrm{C} / 5$ rate. The slightly lower iCE found in the full-cell vs. half-cell can be related to the NVPF counter electrode. While Na metal can supply endless $\mathrm{Na}^{+}$, the parasitic reactions limit the sodium availability in NVPF. Nevertheless, the obtained performance was among the best reported in the literature (Table S3) for full-cell sodium batteries based on the HC anode. Furthermore, the capacity retention rate over cycling was evaluated, while the full-cell was cycled at a $1 \mathrm{C}$ rate (after 5 initial cycles at $\mathrm{C} / 5$ rate). A good retention rate of $94 \%$ was observed after 50 cycles and $78 \%$ after 150 cycles (Fig. 8b, c and S16, ESI).

Lastly, the full-cell rate capacity retention at different asymmetrical rates was evaluated. Fig. $8 \mathrm{~d}$ shows the results obtained by maintaining constant either the discharge (D) or the charge (C), by turn. When constant discharge (D/5) is applied to the cell (the charging current is varied), an initial specific capacity of $100 \mathrm{~mA} \mathrm{~h} \mathrm{~g}^{-1}$ (of NVPF) is obtained at C/5 rate, which slightly decreased when increasing the current $(\mathrm{C} / 2$ rate $)$ and drops to approx. $50 \mathrm{~mA} \mathrm{~h} \mathrm{~g}^{-1}$ at $1 \mathrm{C}$ and to $20 \mathrm{~mA} \mathrm{~h} \mathrm{~g}^{-1}$ at $4 \mathrm{C}$. However, once the cell is cycled back to the $\mathrm{C} / 5$ rate, the capacity reaches a value as high as $96 \mathrm{~mA} \mathrm{~h} \mathrm{~g}^{-1}$, which is close to the initial specific capacity.

On the other hand, when a constant charge (C/5) is applied to the cell, it can be clearly observed that the retention rate obtained is higher than when constant discharge is used (D/5), if considering a proportional current rate for the discharge (in the first case) and charge (in the second case). The retention rate decrease is more significant when a constant discharge is applied. Thus, if a low enough current is used to charge the cell, even high discharge current rates (4D) end up in good performance ( $65 \%$ retention rate). On the contrary, when a fast charge rate is used (i.e., 3C), low performance is obtained (39\% retention rate) even if the discharge current applied is low (i.e., D/5 in this case). Thus, the sodium insertion rate is crucial and seems to occur more slowly than sodium extraction from the anode material. 

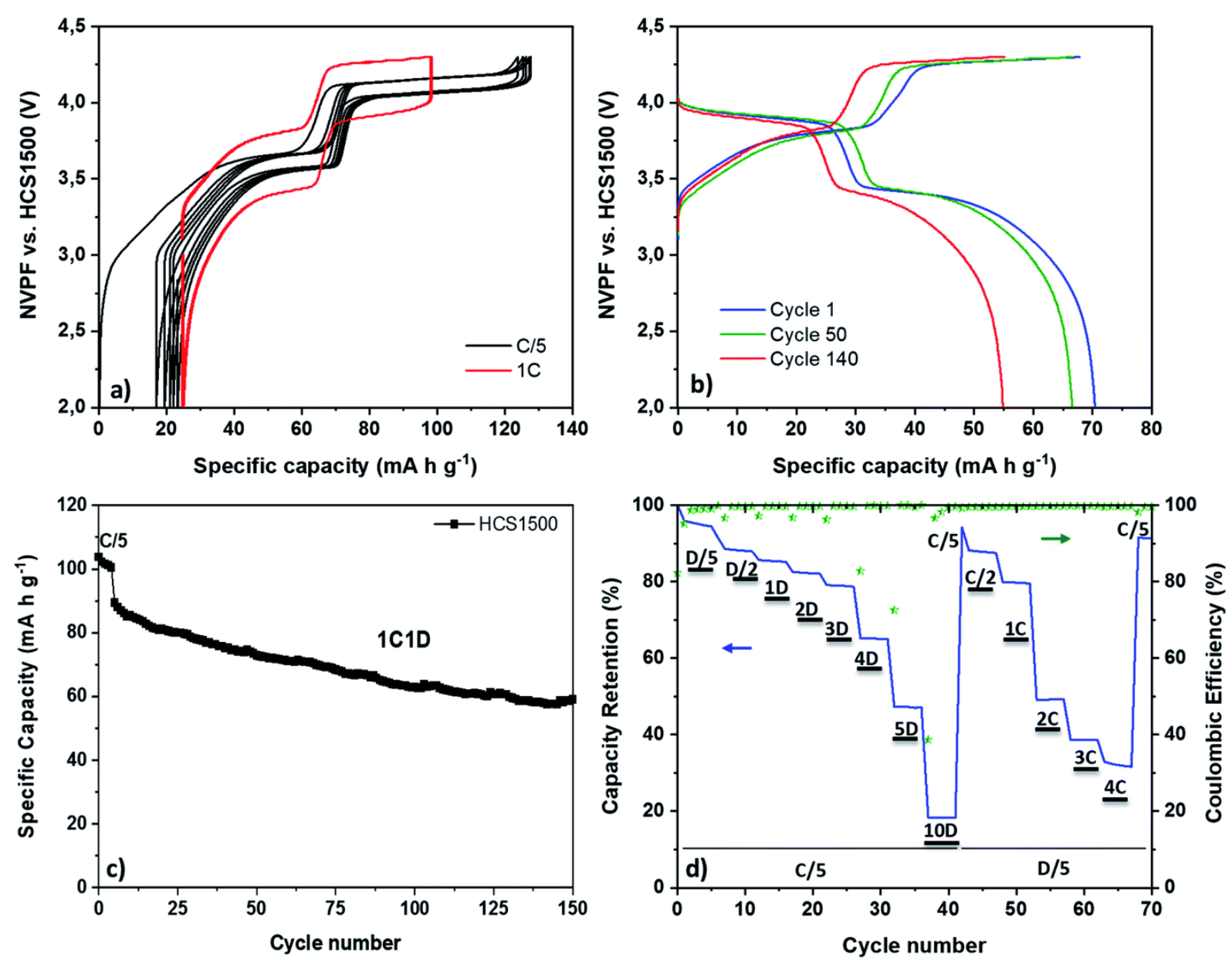

Fig. 8 (a) Full-cell gravimetric capacity of NVPF vs. HCS1500 at C/5 and $1 C$ rates. (b) Fullcell retention of NVPF (vs. HCS1500) specific capacity at 1C after the 1st, 50th and 140th cycles. (c) Cycling stability of HCS1500 in the full-cell at 1C1D. (d) Full-cell rate capacity retention at different asymmetrical rates.

\section{Conclusions}

A series of hard carbon spheres, derived from phenolic resin precursors, were developed in the purpose of understanding the carbon key factors impacting the volumetric capacity and the initial Coulombic efficiency ion Na-ion half-cells. The obtained results were complemented by other lab-made and commercial carbons in order to provide a more general overview in this respect.

With well-defined individual particles (3-4 $\mu \mathrm{m}$, mean size), the obtained hard carbon sphere powders did not require grinding, which is a great advantage from the industrial point of view. By increasing the pyrolysis temperature from $1300{ }^{\circ} \mathrm{C}$ to $1600{ }^{\circ} \mathrm{C}$, the hard carbon physicochemical properties could be progressively adjusted, i.e., the open porosity, surface chemistry 
and active sites were diminished, while the fraction of the closed porosity was enhanced. The decrease in those parameters values had a positive impact on the tapped density, which could be increased from 0.71 to $0.84 \mathrm{~g} \mathrm{~cm}^{-3}$ between 1300 and $1500^{\circ} \mathrm{C}$. Above this temperature, a decrease was observed, which was associated with the closed porosity development. Other parameters impacting the tapped density were identified, like the open porosity (high BET surface area materials) and inter-grain porosity (materials with small particle size in the $\mathrm{nm}$ range), both inducing lower tapped density. Moreover, the carbon morphology proved to be a key parameter too, and random particles appeared to be more efficient than the spherical ones to achieve high tapped density. However, it could be demonstrated that a high tapped density does not necessarily ensure low electrode porosity and high volumetric capacity values; these being conditioned by a low interlayer space, low surface area and low amount of oxygen functional groups/active sites. The carbon spheres proposed herein gather all these requirements and exhibited low electrode porosity after calendaring, which improved progressively from 62 to $41 \%$ with the increase of the pyrolysis temperature. A direct relationship between the electrode porosity and the interlayer space $\left(d_{002}\right)$ could be evidenced. Such low electrode porosity values are very appealing and comparable to that of graphite used in Li-ion batteries.

An iCE value as high as $92 \%$ was found for some HCS carbons, exceeding most of the reported carbons and the PAC2 reference carbon (86\%). The use of several additional lab-made carbons allowed for underlining that such high Coulombic efficiency of the HCS materials can be correlated firstly with the low specific surface area (particularly that of ultra-micropores) and secondly to the low amount of active sites and functional groups, whereas the carbon structure (interlayer space) had a limited impact.

Moreover, due to a high electrode compaction (low electrode porosity) found for the HCS1400 and HCS1500 samples, the volumetric capacity, a key aspect from a practical point of view, surpasses that of PAC2 (293 $\left.\mathrm{mA} \mathrm{h} \mathrm{cm}^{-3}\right)$, reaching 305 and $298 \mathrm{~mA} \mathrm{~h} \mathrm{~cm}^{-3}$, respectively. Based on the high reversible capacity and high Coulombic efficiency found for HCS1500, full-cells were assembled with the NVPF cathode and cycled against the hard carbon material. A specific capacity of $124 \mathrm{~mA} \mathrm{~h} \mathrm{~g}^{-1}$ was delivered in the first cycle along with $86 \%$ iCE. Therefore, very promising electrochemical behavior in both half-cells ( $v s$. Na metal) and full-cells $v s$. cathode material (NVPF) was reached for the carbon spheres, exceeding those of the commercial hard carbon and other lab-made carbons. 
These results reported herein bring new insights on the requirements of hard carbon properties in order to further meet the criteria for their use in NIBs for large-scale industrial production.

\section{Experimental}

\section{Material synthesis}

Hard carbon spheres were obtained by a precipitation polymerization approach, which involves the simple dissolution of phloroglucinol $(4.1 \mathrm{~g})$ and glyoxylic acid $(3.6 \mathrm{~g})$ in water, under stirring, followed by the addition of a triethylenediamine cross-linker (TEDA, $1.8 \mathrm{~g}$ ). The obtained mixture was stirred for few minutes, then was placed on an oil bath to age at room temperature $\left(26^{\circ} \mathrm{C}\right) .{ }^{24}$ After $24 \mathrm{~h}$, a two-phase system was obtained, i.e., a solid phase containing the phenolic resin spheres and a liquid phase containing the solvent, and eventually the unreacted species. The liquid part is simply discarded and the solid part remaining on the bottom of the flask is recovered, dried overnight at $80^{\circ} \mathrm{C}$, and thermally annealed for $1 \mathrm{~h}$ under Ar flow $\left(5^{\circ} \mathrm{C} \mathrm{min}^{-1}\right.$ heating rate) between 1300 and $1600{ }^{\circ} \mathrm{C}$ to obtain the hard carbon spheres (HCS). The materials are denoted HCST (where $T$-indicates the pyrolysis temperature). Such synthesis yielded $\sim 3 \mathrm{~g}$ of carbon ( $\sim 40 \%$ efficiency, Fig. S17, ESI $\dagger$ ); therefore, for large-scale HCS synthesis, the quantities were multiplied by four.

Several supplementary hard carbon materials (HAB1400, TCA1300, TCA1400 and PR1400) having spherical or random morphology have been prepared for comparison purpose, and their synthesis pathways are fully described in the ESI $\uparrow$ part.

\section{Material physico-chemical characterization}

The hard carbon morphology was evaluated by scanning electron microscopy (SEM), which was performed with a FEI Quanta 400 scanning electron microscope equipped with a highresolution low vacuum field emission gun (FEG). Furthermore, using several SEM images, the particle size distribution was determined with the help of ImageJ software, by counting $\sim 600$ particles for each material. The material structure was studied by Raman spectroscopy, X-ray diffraction (XRD) and high-resolution transmission electron microscopy (HRTEM). Raman measurements were performed at room temperature using a LabRAM BX40 (Horiba JobinYvon) spectrometer equipped with a $\mathrm{He}-\mathrm{Ne}$ excitation source (532 $\mathrm{nm}$ wavelength). XRD analysis was performed using a Bruker D8 Advanced diffractometer with flat-plate Bragg- 
Brentano $\theta-\theta$ geometry. The HR-TEM images were obtained with a JEOL instrument (ARM$200 \mathrm{~F}$ model) operating at $200 \mathrm{kV}$.

Textural properties of the hard carbon materials were investigated with a Micromeritics ASAP 2420 instrument using $\mathrm{N}_{2}$ gas as an adsorbate $(77 \mathrm{~K})$ and a Micromeritics ASAP 2020 instrument using $\mathrm{CO}_{2}$ adsorbate $(273 \mathrm{~K})$. Prior to the analysis, the samples were outgassed for $12 \mathrm{~h}$ at $300{ }^{\circ} \mathrm{C}$, under vacuum in the degassing port, and two additional hours on the analysis port. The Brunauer-Emmett-Teller (BET) specific surface area (SSA) was determined from the linear plot in the relative pressure range of $0.05-0.3 P / P_{0}$ for $\mathrm{N}_{2}$ and $0.01-0.03$ for $\mathrm{CO}_{2}$ adsorption.

Calculation of closed and open pore ratio Eqn (1) and (2) were used to calculate the ratio of closed and open pore, respectively. ${ }^{34,51}$

$$
\begin{aligned}
& R_{\mathrm{CP}}(\%)=\left(\left(\frac{1}{d_{\mathrm{He}}}-\frac{1}{2.32}\right) /\left(V_{\mathrm{OP}}+\frac{1}{d_{\mathrm{He}}}\right)\right) \times 100 \\
& R_{\mathrm{OP}}(\%)=\left(V_{\mathrm{OP}} /\left(V_{\mathrm{OP}}+\frac{1}{d_{\mathrm{He}}}\right)\right) \times 100
\end{aligned}
$$

where: $d_{\mathrm{He}}$ is the bulk density measured via He pycnometry, $V_{\mathrm{OP}}$ is the open pore volume obtained from $\mathrm{N}_{2}$ adsorption-desorption measurements, and 2.32 is the density of graphite.

The pycnometer density was measured with an Accupyc 1330 Pycnometer from Micromeritics, working under He gas. A $1 \mathrm{~mL}$ cell (filled 3/4) was used, and the procedure implies 20 purges with 5 repetitions. The material tapped density was determined with the help of a Jolting Volumeter Type STAV II. Around $2 \mathrm{~g}$ of hard carbon was loaded and tapped for 12000 times (3 cycles of 4000 taps).

XPS was used to determine the carbon surface chemical composition and the functional groups in the range of 200-1200 eV by using a VG Scienta SES 2002 spectrometer equipped with a monochromatic X-ray source $(\mathrm{Al} \mathrm{K \alpha}=1486.6 \mathrm{eV})$ and a $\mathrm{G}$ Scienta XM780 monochromator. As XPS is a surface technique, temperature-programmed desorption (TPD) bulk analysis was used to determine the nature and the amount of oxygen-based functional groups and to quantify the amount of active sites in terms of the active surface area (ASA). The measurements were 
performed in a vacuum system equipped with a mass spectrometer (MS) that was constructed in our laboratory. ${ }^{39}$ To determine the oxygen-based functional groups, the samples were heattreated up to $950{ }^{\circ} \mathrm{C}$ (heating rate of $5{ }^{\circ} \mathrm{C} \min ^{-1}$ ), and the gases released were quantitatively analyzed by the mass spectrometer. The mass spectrometer was calibrated using several gases usually desorbed from the carbon surface, i.e., $\mathrm{H}_{2}, \mathrm{H}_{2} \mathrm{O}, \mathrm{CO}, \mathrm{N}_{2}, \mathrm{O}_{2}$ and $\mathrm{CO}_{2}$. Prior to each TPD analysis, a $\mathrm{N}_{2}$ sensibility measurement was performed, which allowed further quantification of the other gases. To quantify the structural defects and the ASA, the materials were first cleaned under vacuum during the first TPD-MS experiment, and then exposed to oxygen introduced at $300{ }^{\circ} \mathrm{C}$ (oxygen pressure: $66.5 \mathrm{~Pa}$ ), which was subsequently chemisorbed for $10 \mathrm{~h}$ to form surface oxygenated complexes. A second TPD was performed at $950{ }^{\circ} \mathrm{C}$ with a $10{ }^{\circ} \mathrm{C} \mathrm{min}-1$ heating rate to determine the amount of oxygenated groups, and finally the ASA. ${ }^{33,52}$

\section{Material electrochemical characterization}

For electrode preparation, the hard carbon powder was mixed with a polyvinylidene fluoride (PVdF) binder and carbon black (SUPER C45, from TIMCAL) conductive additive in a mass ratio of $94: 3: 3$, in the presence of $N$-methyl-2-pyrrolidone (NMP). The obtained slurry was coated on an $\mathrm{Al}$ current collector $(22 \mu \mathrm{m})$. Electrodes with diameters of $1 \mathrm{~cm}$ and a mass loading of $5-10 \mathrm{mg} \mathrm{cm}^{-2}$ were first dried at $70{ }^{\circ} \mathrm{C}$ under vacuum before testing. Electrode calendering was done with a lab press machine BPN-250 model from RJC HOLDINGS CORPORATION. The electrode was passed through a gap using two rolls working in opposite directions several times. The gap is set at a size smaller than the thickness of the electrode to reduce its porosity and thickness. To determine the electrode (apparent) porosity after calendering, the following formula was considered:

Electrode porosity after calendering $=1-$ mass $_{\text {electrode }} \times \frac{\sum_{i} x_{i} \mathrm{wt} \% / d_{\mathrm{He}-} \text { of } y_{i}}{\text { electrode thickness } \times \text { electrode surface }}$

where $x_{1}-94 \mathrm{wt} \%$ of active material (HC) with a density of $y_{1}, x_{2}-3 \mathrm{wt} \%$ of conductive additive (C45) with a density of $y_{2}, x_{3}-3 \mathrm{wt} \%$ of binder (PVDF) with a density of $y_{3}$.

The obtained value of the porosity after calendering was used later to determine the volumetric capacity, considering eqn (4):

$C_{\mathrm{v}}=C_{\mathrm{m}} \times(1-$ electrode porosity after calendering $) \times d_{\mathrm{He}}$ 
where $C_{\mathrm{v}}$ is the volumetric capacity and $C_{\mathrm{m}}$ is the gravimetric capacity.

The electrochemical tests were performed in coin-type cells. The half-cells were assembled in an argon-filled glove box using sodium metal as the counter/reference electrode and a glass fiber separator. The electrolyte consisted of $1 \mathrm{M} \mathrm{NaPF}_{6}$ dissolved in a mixture of ethylene carbonate (EC)/dimethyl carbonate (DMC) with a 1:1 volume ratio. The electrochemical performance was measured using a VMP3 Bio-Logic cycling device. Galvanostatic chargedischarge tests were conducted at a constant current in a voltage window between 0.01 and $2 \mathrm{~V}$ (versus $\mathrm{Na}^{+} / \mathrm{Na}$ ) at $\mathrm{C} / 50$ rate with 1 minute rest between discharge-charge (the theoretical specific capacity was considered $1 \mathrm{C}=372 \mathrm{~mA} \mathrm{~g}^{-1}$ ). The full-cells were also assembled in the glove box using NVPF as the cathode. The material was synthesized according to the procedure described in the ESI. $\uparrow$ It presents a particle size of about 5-30 $\mu \mathrm{m}$ and a high crystalline structure (Fig. S18 $\dagger$ ). The NVPF electrode was composed of NVPF/C45/PVDF (92/4/4 wt\%) and the NMP solvent, and was tested against the HCS electrode with a mass ratio between 2 and 2.5 (NVPF/HC). The electrolyte employed was $1 \mathrm{M} \mathrm{NaPF}_{6}$ in EC:DMC (1:1). All experiments were conducted at room temperature, and the potentials are expressed relative to $\mathrm{Na}$ metal (vs. $\left.\mathrm{Na}^{+} / \mathrm{Na}\right)$.

\section{Conflicts of interest}

There are no conflicts to declare.

\section{Acknowledgements}

This work was performed in the frame of RS2E (French research network on electrochemical energy storage), and the Laboratory of Excellency for Electrochemical Energy Storage, STORE-EX. The authors thank DGA (Direction Générale de l'Armement, No. 201660 0050) and Region Alsace (No. 618342) for the financial support of this work. We also thank Dr Loic Vidal (HR-TEM images), Dr Jean-Marc Le Meins (XRD data) and Dr Philippe Fioux (XPS analysis) for technical support via IS2M technical platforms.

\section{References}

1. A. Gomez-Martin , J. Martinez-Fernandez, M. Ruttert, M. Winter, T. Placke and J. Ramirez-Rico , Chem. Mater., 2019, 31, 7288 -7299.

2. J. Górka , C. Vix-Guterl and C. Matei Ghimbeu , C, 2016, 2 , 24 Search PubMed . 
3. L. Wu , D. Buchholz , C. Vaalma , G. A. Giffin and S. Passerini , ChemElectroChem, 2016, 3 , 292 -298.

4. K. Wang, Y. Jin, S. Sun, Y. Huang, J. Peng, J. Luo, Q. Zhang, Y. Qiu , C. Fang and J. Han , ACS Omega, 2017, 2 , 1687 -1695.

5. R. Väli , A. Jänes, T. Thomberg and E. Lust , J. Electrochem. Soc., 2016, 163 , A1619 -A1626.

6. C. Bommier, W. Luo, W.-Y. Gao, A. Greaney, S. Ma and X. Ji , Carbon, 2014, 76, $165-174$.

7. Q. Wang, X. Ge, J. Xu , Y. Du, X. Zhao, L. Si and X. Zhou , ACS Appl. Energy Mater., 2018, $1,6638-6645$.

8. A. Beda , C. Villevieille, P.-L. Taberna, P. Simon and C. M. Ghimbeu, J. Mater. Chem. A, 2020, 8, 5558 -5571.

9. A. Beda , P.-L. Taberna , P. Simon and C. Matei Ghimbeu , Carbon, 2018, 139 , 248 257.

10. Y. Li , L. Mu , Y.-S. Hu , H. Li , L. Chen and X. Huang, Energy Storage Materials, 2016, 2, $139-145$.

11. B. Zhang, C. M. Ghimbeu, C. Laberty, C. Vix-Guterl and J.-M. Tarascon, Adv. Energy Mater., 2016, 6, 1501588.

12. D. Saurel , B. Orayech , B. Xiao, D. Carriazo , X. Li and T. Rojo , Adv. Energy Mater., 2018, 8, 1703268.

13. C. Bommier, D. Mitlin and X. Ji , Prog. Mater. Sci., 2018, 97, 170 -203.

14. X. Chen, Y. Zheng, W. Liu , C. Zhang, S. Li and J. Li , Nanoscale, 2019, 11, 22196 $-22205$.

15. K. C. Klavetter, J. P. de Souza, A. Heller and C. Buddie Mullins, J. Mater. Chem. A, 2015, 3, $5829-5834$.

16. D. Lin , Z. Lu , P.-C. Hsu , H. R. Lee, N. Liu, J. Zhao , H. Wang, C. Liu and Y. Cui , Energy Environ. Sci., 2015, 8, 2371 -2376.

17. E. Irisarri , N. Amini , S. Tennison, C. M. Ghimbeu , J. Gorka , C. Vix-Guterl , A. Ponrouch and M. R. Palacin , J. Electrochem. Soc., 2018, 165 , A4058 -A4066.

18. A. van Bommel and R. Divigalpitiya , J. Electrochem. Soc., 2012, 159 , A1791.

19. W. Haselrieder, S. Ivanov , D. K. Christen , H. Bockholt and A. Kwade, ECS Trans., 2013, $50,59-70$.

20. C. Meyer, H. Bockholt, W. Haselrieder and A. Kwade, J. Mater. Process. Technol., 2017, 249, $172-178$.

21. H. Wang, Z. Shi , J. Jin , C. Chong and C. Wang , J. Electroanal. Chem., 2015, 755 , $87-91$.

22. H. Tang, M. Wang, T. Lu and L. Pan , Ceram. Int., 2017, 43 , 4475 -4482.

23. Y. Jin , S. Sun, M. Ou , Y. Liu, C. Fan, X. Sun, J. Peng, Y. Li, Y. Qiu, P. Wei , Z. Deng, Y. Xu , J. Han and Y. Huang, ACS Appl. Energy Mater., 2018, 1, 2295 -2305.

24. A. Maetz , L. Delmotte , G. Moussa , J. Dentzer , S. Knopf and C. M. Ghimbeu , Green Chem., 2017, 19 , 2266-2274.

25. C.Matei Ghimbeu, A.Beda, P.-L.Taberna, P.Simon, M.Morcrette and F.Rabuel, Matériau carboné, son utilisation dans des batteries, son procédé de fabrication et une électrode le comprenant, France Patent, FR1914354, 2019.

26. H. Lyu, B. Gao , F. He, C. Ding, J. Tang and J. C. Crittenden, ACS Sustainable Chem. Eng., 2017, 5 , 9568 -9585 .

27. K. Tang, L. Fu, R. J. White, L. Yu , M.-M. Titirici, M. Antonietti and J. Maier, Adv. Energy Mater., 2012, 2 , $873-877$.

28. W. Wang, W. Li , S. Wang, Z. Miao, H. K. Liu and S. Chou, J. Mater. Chem. A, 2018, 6, 6183-6205. 
29. G. E. Amidon , P. J. Meyer and D. M. Mudie, Developing Solid Oral Dosage Forms, Y. Qiu, Y. Chen, G. G. Z. Zhang, L. Yu and R. V. Mantri, Academic Press, Boston, 2017, pp. 271-293.

30. J. R. Dahn, W. Xing and Y. Gao , Carbon, 1997, 35 , 825-830.

31. T. Zhang, J. Mao, X. Liu , M. Xuan, K. Bi , X. L. Zhang, J. Hu, J. Fan, S. Chen and G. Shao, RSC Adv., 2017, $7,41504-41511$ RSC .

32. C. Bommier, T. W. Surta, M. Dolgos and X. Ji , Nano Lett., 2015, 15, 5888 -5892.

33. C. Matei Ghimbeu , J. Górka, V. Simone , L. Simonin , S. Martinet and C. Vix-Guterl , Nano Energy, 2018, 44 , 327 -335.

34. E. R. Buiel , A. E. George and J. R. Dahn , Carbon, 1999, 37 , 1399 -1407.

35. Y. Li , Y. Lu , Q. Meng, A. C. S. Jensen, Q. Zhang, Q. Zhang, Y. Tong, Y. Qi , L. Gu , M.-M. Titirici and Y.-S. Hu , Adv. Energy Mater., 2019, 9, 1902852.

36. M. Dahbi , M. Kiso , K. Kubota, T. Horiba , T. Chafik , K. Hida , T. Matsuyama and S. Komaba, J. Mater. Chem. A, 2017, 5 , 9917 -9928.

37. Y. Morikawa, S. Nishimura, R. Hashimoto , M. Ohnuma and A. Yamada, Adv. Energy Mater., 2020, $10,1903176$.

38. J. L. Figueiredo, M. F. R. Pereira, M. M. A. Freitas and J. J. M. Órfão, Carbon, 1999, 37, $1379-1389$.

39. G. Moussa , C. Matei Ghimbeu , P.-L. Taberna, P. Simon and C. Vix-Guterl, Carbon, 2016, $105,628-637$.

40. A. Beda , C. Villevieille , P.-L. Taberna , P. Simon and C. M. Ghimbeu, J. Mater. Chem. A, 2020, 8, $5558-5571$.

41. C. Nita , M. Bensafia, C. Vaulot, L. Delmotte and C. Matei Ghimbeu, Carbon, 2016, $109,227-238$.

42. C. Matei Ghimbeu , B. Zhang, A. Martinez de Yuso , B. Rety and J.-M. Tarascon , Carbon, 2019, 153, $634-647$.

43. J. J. Kipling, J. N. Sherwood, P. V. Shooter and N. R. Thompson, Carbon, 1964, 1 , $321-328$.

44. E. M. Lotfabad , J. Ding, K. Cui , A. Kohandehghan , W. P. Kalisvaart , M. Hazelton and D. Mitlin , ACS Nano, 2014, 8 , 7115-7129.

45. E. Irisarri , A. Ponrouch and M. R. Palacin , J. Electrochem. Soc., 2015, 162 , A2476 A2482.

46. N. Sun , Z. Guan, Y. Liu , Y. Cao, Q. Zhu , H. Liu , Z. Wang, P. Zhang and B. Xu , Adv. Energy Mater., 2019, $9,1901351$.

47. S. Qiu , L. Xiao, M. L. Sushko, K. S. Han, Y. Shao, M. Yan, X. Liang, L. Mai , J. Feng, Y. Cao, X. Ai , H. Yang and J. Liu , Adv. Energy Mater., 2017, 7, 1700403.

48. C. Nita , B. Zhang, J. Dentzer and C. Matei Ghimbeu , J. Energy Chem., 2020, 10.1016/j.jechem.2020.08.065.

49. J. Wang, J. Polleux , J. Lim and B. Dunn , J. Phys. Chem. C, 2007, 111 , 14925 -14931.

50. G. Yan, S. Mariyappan, G. Rousse, Q. Jacquet, M. Deschamps , R. David, B. Mirvaux , J. W. Freeland and J.-M. Tarascon , Nat. Commun., 2019, 10 , 1 -12.

51. J. Conder, C. Vaulot, C. Marino, C. Villevieille and C. M. Ghimbeu, ACS Appl. Energy Mater., 2019, 2, 4841 -4852.

52. F. Béguin , F. Chevallier , C. Vix-Guterl , S. Saadallah , V. Bertagna , J. N. Rouzaud and E. Frackowiak, Carbon, 2005, 43 , 2160 -2167 . 